\title{
EVALUATION OF THE COMPUTERIZED UTILITIES AND ENERGY MONITORING AND CONTROL SYSTEM INSTALLED AT \\ THE U.S. ARMY, EUROPE, 222D BASE SUPPORT BATTALION, BAUMHOLDER, GERMANY
}

\author{
M. B. Gettings \\ S. L. Purucker
}

Energy Division

Oak Ridge National Laboratory

November 1992

OAK RIDGE NATIONAL LABORATORY

Oak Ridge, Tennessee 37831-6285 managed by

MARTIN MARIETTA ENERGY SYSTEMS, INC.

for the

U.S. DEPARTMENT OF ENERGY

under Contract No. DE-AC05-84OR21400 


\section{CONTENTS}

LIST OF FIGURES $\ldots \ldots \ldots \ldots \ldots \ldots \ldots \ldots \ldots \ldots \ldots \ldots \ldots \ldots \ldots$

LIST OF TABLES $\ldots \ldots \ldots \ldots \ldots \ldots \ldots \ldots \ldots \ldots \ldots \ldots \ldots \ldots \ldots \ldots$

ACKNOWLEDGMENTS $\ldots \ldots \ldots \ldots \ldots \ldots \ldots \ldots \ldots \ldots \ldots \ldots \ldots \ldots \ldots$

EXECUTTVE SUMMARY $\ldots \ldots \ldots \ldots \ldots \ldots \ldots \ldots \ldots \ldots \ldots \ldots \ldots \ldots$

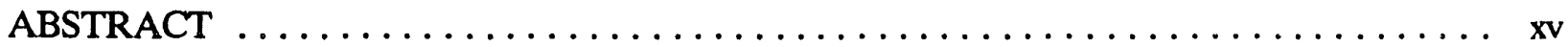

1. INTRODUCTION $\ldots \ldots \ldots \ldots \ldots \ldots \ldots \ldots \ldots \ldots \ldots \ldots \ldots \ldots \ldots \ldots \ldots$

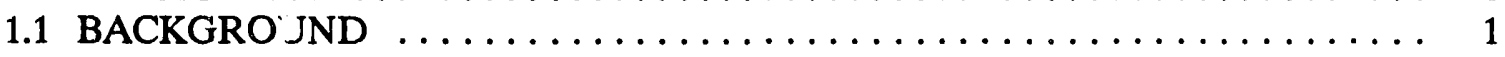

1.2 SCOPE (STATEMENT OF WORK) $\ldots \ldots \ldots \ldots \ldots \ldots \ldots \ldots \ldots \ldots \ldots$

2. UTILITIES AND ENERGY MONITORING AND CONTROL SYSTEM

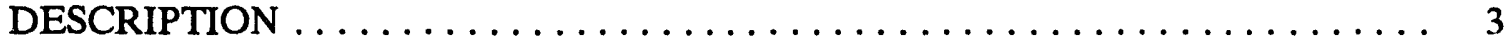

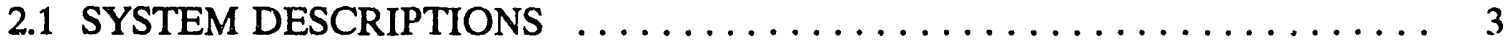

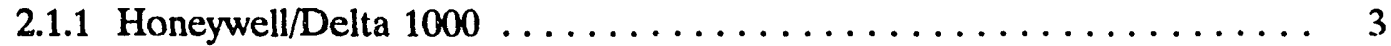

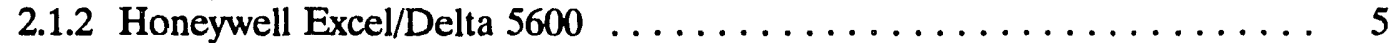

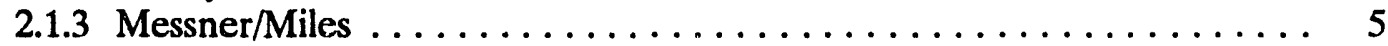

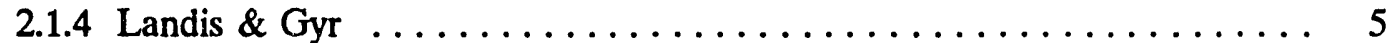

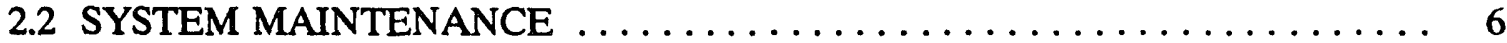

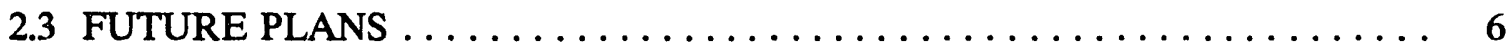

3. EVALUATION OF PROJECT DOCUMENTATION $\ldots \ldots \ldots \ldots \ldots \ldots \ldots$

4. ASSESSMENT OF SITE AND PHYSICAL CONDITIONS $\ldots \ldots \ldots \ldots \ldots \ldots \ldots \ldots$

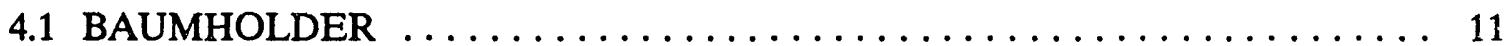

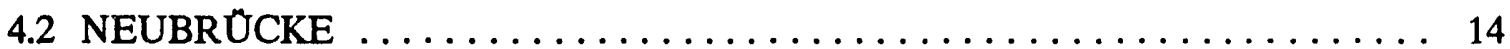

4.3 NAHBOLLENBACH STORAGE AREA $\ldots \ldots \ldots \ldots \ldots \ldots \ldots \ldots \ldots \ldots$

4.4 IDAR-OBERSTEIN FAMILY HOUSING $\ldots \ldots \ldots \ldots \ldots \ldots \ldots \ldots \ldots \ldots \ldots$

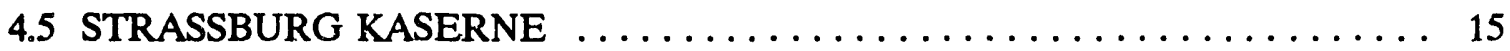

5. ANALYSIS OF POTENTIAL ENERGY SAVINGS $\ldots \ldots \ldots \ldots \ldots \ldots \ldots \ldots$

6. UTILITIES AND ENERGY MONITORING AND CONTROL SYSTEM

APPLICATIONS AND THEIR SAVINGS . . . . . . . . . . . . . . . . . . 29

6.1 APPLICATION DESCRIPTION $\ldots \ldots \ldots \ldots \ldots \ldots \ldots \ldots \ldots \ldots \ldots \ldots \ldots$

6.1.1 Day/Night Setback-Optimum Start/Stop . . . . . . . . . . . . . . 29

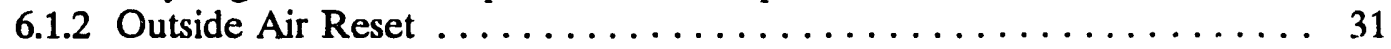

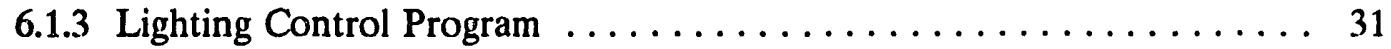

6.1.4 Demand Limiting $\ldots \ldots \ldots \ldots \ldots \ldots \ldots \ldots \ldots \ldots \ldots \ldots \ldots \ldots \ldots \ldots \ldots \ldots$

6.1.5 Summer/Winter Operation Monitoring (Switchover) $\ldots \ldots \ldots \ldots \ldots 32$ 
6.1.6 Start/Stop of Domestic Hot Water Circulation Pumps (Not

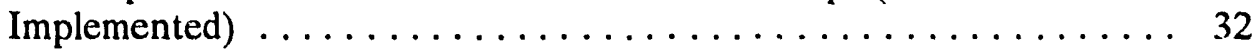

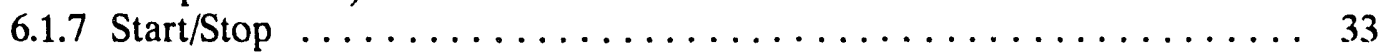

6.2 SUMMARY OF APPLICATION SAVINGS AND COMPARISON WITH

CONSUMPTION ......................... 33

7. GENERAL ASSESSMENT OF UTILITIES AND ENERGY MONITORING AND

CONTROL SYSTEM BENEFITS $\ldots \ldots \ldots \ldots \ldots \ldots \ldots \ldots \ldots \ldots \ldots \ldots \ldots$

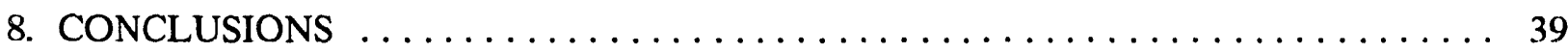

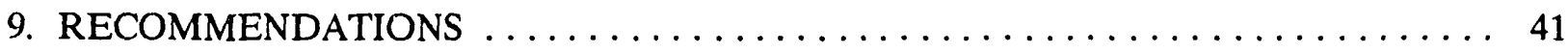

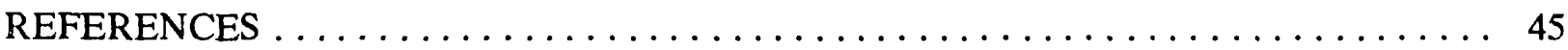




\section{LIST OF FIGURES}

Fig. 1. Honeywell Excel/Delta 5600 system and Honeywell/Delta 1000 terminal and one of three circuitry cabinets $\ldots \ldots \ldots \ldots \ldots \ldots \ldots \ldots \ldots \ldots \ldots \ldots \ldots \ldots$

Fig. 2. Messner/Miles utilities and energy monitoring and control system control room . . . 4

Fig. 3. Location of installations comprising the Baumholder military community $\ldots \ldots \ldots 12$

Fig. 4. Baumholder community total energy consumption by fuel . . . . . . . . . . . . 19

Fig. 5. Baumholder community normalized total and thermal energy consumption . . . . . 20

Fig. 6. Baumholder community monthly total energy consumption $\ldots \ldots \ldots \ldots \ldots 22$

Fig. 7. Baumholder community normalized monthly total energy consumption $\ldots \ldots \ldots . \ldots 23$

Fig. 8. Total 1990 energy consumptions by installation $\ldots \ldots \ldots \ldots \ldots \ldots \ldots \ldots$

Fig. 9. 1990 electrical energy consumptions by installation $\ldots \ldots \ldots \ldots \ldots \ldots \ldots \ldots \ldots$ 


\section{LIST OF TABLES}

Table 1. Utilities and energy monitoring and control systems at the Baumholder military

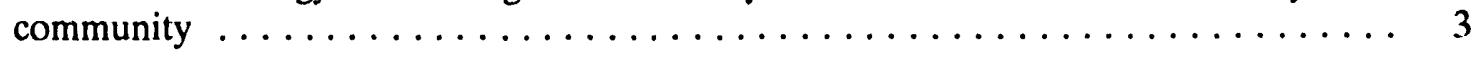

Table 2. Major energy-related projects at the Baumholder military community $\ldots \ldots \ldots 13$

Table 3. Baumholder community energy consumption by fuel type (MBtu/year) $\ldots \ldots \ldots 18$

Table 4. Reported 1990 energy consumptions for Baumholder installations (MTtu/year) . . . 24

Table 5. Comparison of 1990 community normalized energy consumptions . . . . . . . . 27

Table 6. Conservation applications in effect at Baumholder $\ldots \ldots \ldots \ldots \ldots \ldots$

Table 7. Estimated 1990 Utilities and energy monitoring and control system application

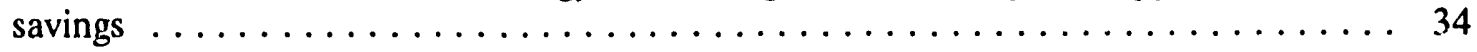




\section{ACKNOWLEDGMENTS}

The authors would like to acknowledge the assistance and support of Werner Schneider, Ulbig Reinhardt, and staff of the Utilities Division of the 222D Base Support Battalion at Baumholder, and of Jeff Mitchell at Headquarters, U.S. Army, Europe, Heidelberg, Germany. We would also like to acknowledge the logistical support of Gary Briggs and Bill McBrayer of the Martin Marietta Energy Systems, Inc., European Office as well as the technical reviews provided by Marty Broders and Ben McConnell. 


\section{EXECUTIVE SUMMARY}

Under the provisions of Interagency Agreement DOE No. 1938-B090-A1, between the U.S. Department of Energy (DOE) and the U.S. Army in Europe, Martin Marietta Energy Systems, Inc. is evaluating utilities and energy monitoring and control systems (UEMCSs) installed at selected U.S. Army installations in Europe. Evaluations of the overall performance and energy efficiency of UEMCSs installed at U.S. Army installations in Heidelberg, Goppingen, and Pirmasens, Germany, have already been completed. This report presents the results of an evaluation of the UEMCS installed at the 222D Base Support Battalion (BSB) in Baumholder, Germany, which is operated by the Directorate of Engineering and Housing (DEH), Utilities Division.

The Baumholder BSB consists of numerous installations located as far as 63 miles from the principal installation at Baumholder. Only five facilities within these installations currently have support from four essentially separate UEMCSs. A Messner/Miles and two Honeywell systems perform traditional UEMCS functions associated with district heating, while a Landis \& Gyr UEMCS is used exclusively for electrical demand limiting and exterior lighting control. In addition to these four systems, a computer-assisted system is used by the Sanitation Department at Baumholder to monitor and control two water-treatment plants.

The Honeywell/Delta 1000 system, with 2500 points, services approximately 100 buildings in Baumholder's Smith Barracks facility, including troop billets and administration buildings. The system applies the start/stop function to the district heat hot water pumps while monitoring locally controlled mixing of heating hot water, outside air reset, optimum start/stop, and setback functions. Installed in 1982-1983, the Honeywell/Delta 1000 system is the oldest UEMCS at the community, and is presently "saturated" because of the limited capacity of its central processing unit (CPU). In addition, the wire-line data transmission media (DTM) installed with the system were placed on overhead lines between buildings and are easily damaged, while other existing telephone lines also used are about 30 year: old and not very reliable.

Similar in function to the 1000 system, the Honeywell Excel/Delta 5600 UEMCS has 600 points servicing 30 buildings in the Neubrücke Hospital area. Installed during 1986-1987 during the renovation of the steam distribution lines at the facility, the Honeywell 5600 system is fairly reliable, though the Army-owned telephone cables, which were formerly part of the German telephone system, do present some problems.

The Messner/Miles UEMCS, with about 1500 points, serves 70 buildings at Nahbollenbach, Strassburg Kaserne and family housing, and Idar-Oberstein family housing. Installed during 1988 at the three locations, the Messner/Miles system was designated "DDC" (direct digital control), implying at most a supervisory role for the central computer. The system also uses a wire-line DTM. though no problems were reported associated with communications.

The Landis \& Gyr demand-limiting UEMCS was installed at Baumholder during 1987, but only used in this mode since 1989. Initially only the start/stop function was exercised in controlling exterior lighting via a central photocell. In 1989, demand limiting began using a ripple control communication system over existing cabling to individual bu:ildings. The system is currently able to limit electrical consumption of night heat storage units, electric radiators, transformer station heat, hot water generators, exterior lighting, and clothes dryers in family housing. Though duty cycling is possible with the system, none is implemented because sufficient load is not yet connected to the system. 
Historical energy consumption data was available for only the community as a whole, making identification of UEMCS savings from individual installations or facilities difficult. However, energy consumptions by fuel type and installation were obtained for fiscal year 1990, allowing some analyses.

The clearest trend indicated by the data is the impact of converting heating plants from coal and oil to hot water district heat. From 1987 to 1990, thermal energy consumption decreased 21\%, though this does not account for the losses associated with generating the district heat. Normalized electrical energy consumption (MBtu/ $/ \mathrm{kt}^{2}$ ) increased $13 \%$ between 1985 and 1988 , then decreased $7 \%$ from 1988 to 1990 . No information oblained could explain this reversal in electrical consumption trends.

No historical data was available during initial operation of the Honeywell 1000 UEMCS, making any data-based estimates of UEMCS savings impossible. Part of the decrease in thermal energy consumption seen between 1986 and 1987 may be because of installation of the Honeywell 5600 system, because no other major energy conserving project was introduced during this same time period. However, to ascribe all the thermal energy reduction during this period to the UEMCS would imply a $100 \%$ savings of energy for the attached building area. The installation of the Messner/Miles system occurred almost concurrently with the conversion to district heat, likely eclipsing the effect of the UEMCSs.

Engineering estimates produced for this report from data obtained from the site visit predict a $6 \%$ reduction in total community energy consumption from UEMCS implementation, saving 1.9 million DM annually. However, less than $40 \%$ of the total community building area is serviced by a UEMCS.

Major conclusions from the study include the following:

- The Baumholder Utilities Division has acted wisely in implementing UEMCS equipment at its largest energy consuming installations, particularly Baumholder.

- Substantial reductions in thermal energy consumption over the entire Baumholder military community have occurred from 1986 through 1990 because of implementation of UEMCS equipment and the conversion from local fossil fuel boilers to purchased district heat. Thermal consumption has decreased nearly $21 \%$ over this time. If an $85 \%$ efficient district heating plant is assumed, this decrease is reduced to $10 \%$ of the source fuels.

- Lack of annual energy consumption data by individual installation makes direct association of energy reductions to the implementation of specific UEMCSs difficult. The total absence of any data prior to 1985 prevents identifying the effects of the UEMCS at Baumholder, the largest energy consumer in the community.

- Facilities currently under UEMCS control have normalized thermal consumptions consistent with well managed systems although the value for Strassburg Kaserne is higher than at the other sites.

- Baumholder's 1990 normalized total and thermal energy consumptions are higher than at two other communities studied. However, the values are not inordinately high and will iikely decrease as a larger fraction of the Smith Barracks is connected to the UEMCS. 
- Thermal energy consumption at the community's missile sites is significantly higher than at other facilities.

- The community's greatest UEMCS-related energy savings result from application of optimum start/stop and day-night setback at its Smith Barracks facility within the Baumholder installation.

- The community's Utilities Division plans for UEMCS expansion are correctly focused on its largest energy consuming facilities.

Recommendations for future expansion and utilization of UEMCSs include the following items:

- Expand use of the demand-limiting capability of the Landis \& Gyr UEMCS.

- Increase capacity of the Honeywell 1000 UEMCS CPU by either using available memory on the Honeywell 5600 computer or upgrading the present 1000 system.

- Provided there exists available capacity with existing UEMCS central computers, expand UEMCS control at Baumholder to include the hospital, the Quarter Master area, and Wetzel and Smith family housing.

- Have the present UEMCS equipment provide shutoff of domestic hot water circulation pumps during night-time hours in family housing complexes and applicable adminstrative buildings.

- Consider the economics of extending the Honeywell 5600 UEMCS servicing the Neubrücke Hospital complex to include the associated family housing.

- Complete intended installation of heating hot water and potable water leak detection equipment.

- Begin tracking annual energy consumptions and costs by fuel for each installation.

- Initiate a moderate effort to coordinate energy awareness and to ensure application of sound energy conservation practices at the end-user level.

- Have the DEH, in coordination with the Directorate of Information and Management, test and evaluate the condition and quality of data transmission lines and repair deficiencies or replace as required. 


\begin{abstract}
Under the provisions of an interagency agreement between the U.S. Army and the U.S. Department of Energy, Martin Marietta Energy Systems, Inc., through the Oak Ridge National Laboratory, is evaluating the utilities and energy monitoring and control systems (UEMCSs) installed at the 222D Base Support Battalion (BSB) at Baumholder, Germany. This evaluation relies on examination of existing data and information to determine the effectiveness of the UEMCSs. The Baumholder BSB consists of numerous installations located as far as 63 miles from the principal installation at Baumholder. Only five facilities within these installations currently have support from four essentially separate UEMCSs. A Messner/Miles and two Honeywell systems, which combined have 4600 points serving 200 buildings, perform traditional UEMCS functions associated with district heating, while a Landis \& Gyr UEMCS is used exclusively for electrical demand limiting and exterior lighting control. At the time of a site visit, the oldest of the Honeywell systems had its memory saturated, preventing further extension of UEMCS applications at the facility served. Demand limiting with the Landis \& Gyr system began in 1989. Additional load is yet available for connection to the system. Total energy consumption at the community has steadily decreased since 1986 because of the implementation of UEMCS and the conversion to district heat. However, lack of annual energy consumption data by individual installation makes direct association of energy reductions to the implementation of specific UEMCSs difficult. Engineering estimates predict approximately a $6 \%$ annual energy savings associated with the UEMCSs or DM 1.9 million. However, less than $40 \%$ of the total community building area is connected. Opportunities for additional savings are available through (1) expanded use of demand limiting, (2) increased memory for the older Honeywell system to allow extending its application at the Smith Barracks facility and facilities nearby, (3) use of available UEMCS equipment to shut off the domestic hot water circulation pumps at night, (4) extension of UEMCS control at the Neubrücke Hospital complex, and (5) installation and utilization of heating hot water and potable hot water leak detection equipment. In addition, a moderate effort to coordinate energy awareness programs and track energy consumption by facility should be undertaken and data transmission lines associated with the UEMCS inspected and repaired or replaced as required.
\end{abstract}




\section{INTRODUCTION}

\subsection{BACKGROUND}

Under the provisions of Interagency Agreement DOE No. 1938-B090-A1, between the U.S. Department of Energy (DOE) and the U.S. Army in Europe (USAREUR), Martin Marietta Energy Systems, Inc. is providing research and development support and technical assistance in the areas of computer science, information engineering, energy studies, engineering, and systems development. One of the initial projects authorized under this interagency agreement calls for the evaluation of utilities and energy monitoring and control systems (UEMCSs) installed at selected U.S. Army installations in Europe. Evaluations of the overall performance and energy efficiency of UEMCSs installed at U.S. Army installations in Heidelberg, Goppingen, and Pirmasens, Germany, have been completed and plans are currently under way to evaluate the UEMCSs at two additional sites in Grafenwohr and Hohenfels, Germany. This report presents the results of an evaluation of the UEMCSs installed at the 222D Base Support Battalion (BSB) in Baumholder, Germany, which is operated by the Directorate of Engineering and Housing (DEH), Utilities Division.

\subsection{SCOPE (STATEMENT OF WORK)}

The Oak Ridge National Laboratory (ORNL) was selected by Headquarters, USAREUR, $\mathrm{DEH}$, Utilities and Energy Branch, in Heidelberg to evaluate the overall effectiveness and energy efficiency of UEMCSs at U.S. Army installations in Germany. This report documents the evaluation of the UEMCSs installed at the 222D Base Support Battalion (BSB) in Baumholder. This evaluation rclied upon existing data and information and did not involve the installation of metering and instrumentation for the purpose of measuring installation energy use.

The primary purpose of this evaluation was to document the current application of the UEMCSs at Baumholder; identify the associated energy, cost, and operation and maintenance savings; and examine the potential for extending or implementing additional UEMCS strategies, particularly those found effective at the 26th Support Group, Heidelberg. Current operation of the systems was confirmed by examination of available documentation; a ten-day site visit, which included physical examination of the system as well as in-depth interviews with system operators, supervisors, and maintenance personnel; and responses to subsequent data requests. Energy and cost savings for individual UEMCS functions were estimated by engineering calculations and compared with energy consumption data. However, because of limited availability of facility-specific data, such comparisons provide only minimal insight. Benefits of the UEMCSs not directly related to energy savings are also discussed. Extension of the present UEMCSs to additional facilities within the community are cxamined, necessitating brief examinations of the facilities not currently serviced by UEMCSs. Functions found cost effective in Heidelberg and applicable to the Baumholder community are aiso discussed. 


\section{UTILITIES AND ENERGY MONITORING AND CONTROL SYSTEM DESCRIPTION}

\subsection{SYSTEM DESCRIPTIONS}

Four essentially separate UEMCSs exist in the Baumholder military community. Table 1 indicates which facilities each UEMCS services and the period during which they were installed.

Table 1. Utilities and energy monitoring and control systems at the Baumholder military community

\begin{tabular}{||l|l|c||}
\hline \multicolumn{1}{|c|}{ System } & \multicolumn{1}{|c|}{ Facilities served } & Installation date \\
\hline \hline Honeywell/Delta 1000 & $\begin{array}{l}\text { Smith Barracks } \\
\text { (Baumholder) }\end{array}$ & $1982-1983$ \\
\hline Honeywell Excel/Delta 5600 & Neubrücke Hospital & $1986-1987$ \\
\hline Landis \& Gyr & Baumholder & $1987 / 1989$ \\
\hline Messner/Miles & $\begin{array}{l}\text { Idar-Oberstein } \\
\text { Strassburg Kaserne } \\
\text { Nahbollenbach Depot }\end{array}$ & $1988-1989$ \\
\hline
\end{tabular}

The Honeywell and Messner/Miles systems perform traditional UEMCS functions associated with district heating, while the Landis \& Gyr UEMCS is used exclusively for electrical demand limiting and cxterior lighting control. More detailed descriptions are given below. In addition to these four systems, a computer-assisted system is used by the Sanitation Department at Baumholder to monitor and control two water treatment plants. Remotely monitored parameters include water quality, $\mathrm{H}$, chlorine and fluorine levels, and turbidity, as well as the water levels in reservoirs.

\subsubsection{Honeywell/Delta 1000}

The Honeywell/Delta 1000 system, with 2500 points, services approximately 100 buildings in Baumholder's Smith Barracks facility, including troop billets and administration buildings. The right half of Fig. 1 shows the terminal and one of three circuitry cabinets associated with the system. The Honeywell 1000 applies the start/stop function to the district heat hot water pumps while monitoring locally controlled mixing of heating hot water, outside air $(O A)$ reset, optimum start/stop, and setback functions. It was indicated that this particular system had no "distributed intelligence," which presented concern when the central computer became inoperable. However, at least the OA reset function was said to remain functional under such instances, placing some doubt regarding which functions were actually controlled by the UEMCS as opposed to falling under local control. 


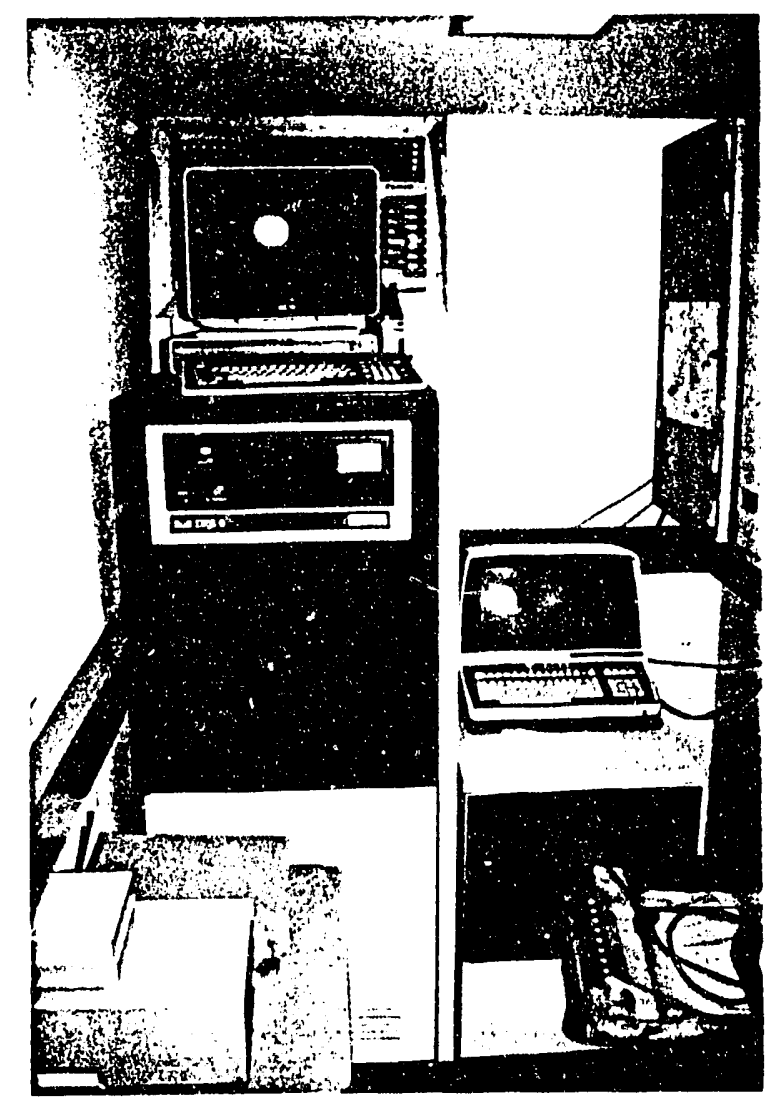

Fig. 1. Honeywell Excel/Delta 5600 system (left) and Honeywell/Delta 1000 terminal and one of three circuitry cabincts (right).

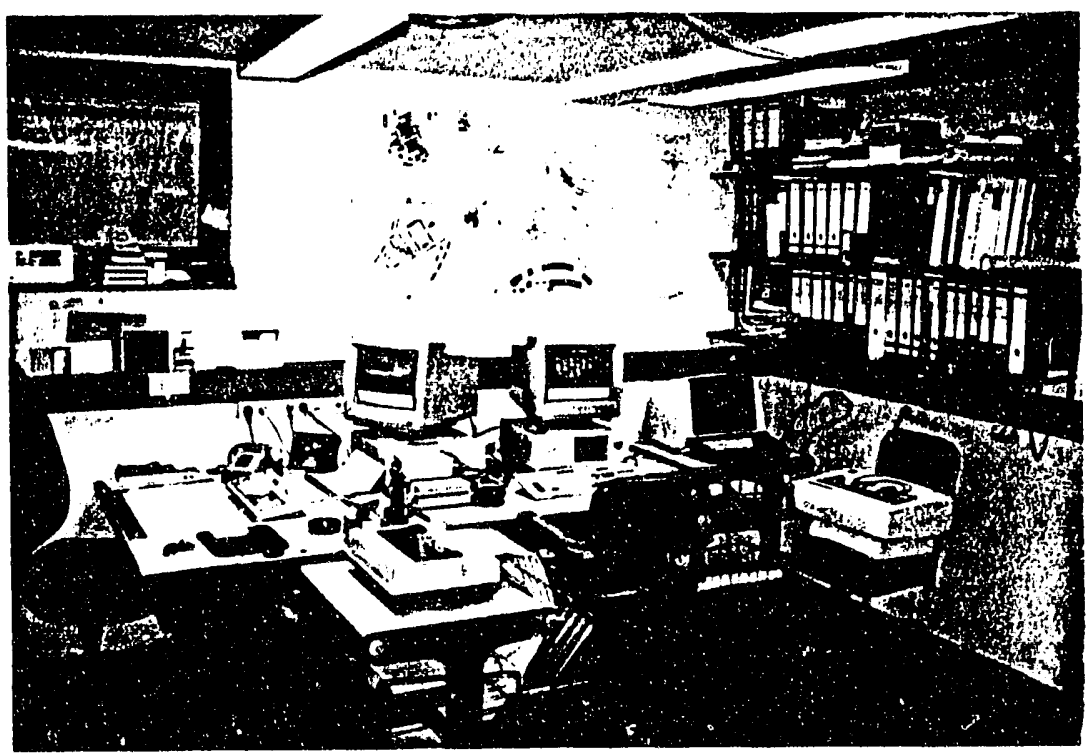

Fig. 2. Messner/Miles utility and energy monitoring and control system control room. 
Installed in 1982-1983 the Honeywell 1000 system is the oldest UEMCS at the community, and problems currently exist. It is presently "saturated" because of the limited capacity of its central processing unit (CPU), though the possibility exists of utilizing available capacity of the Honeywell Excel/Delta/5600 computer to further expand its use. At the time of the site visit, the Honeywell $1000 \mathrm{CPU}$ had altogether failed and repair was not yet imminent. In addition, the wire-line data transmission media (DTM) installed with the system were placed on overhead lines between buildings and are easily damaged, while other existing telephone lines are about 30 years old and not reliable. Whenever there is need to repair or replace steam lines, the DTM are also replaced with new cable.

\subsubsection{Honeywell Excel/Delta 5600}

Similar in function to the system at Smith Barracks, the Honeywell Excel/Delta 5600 UEMCS has 600 points servicing 30 buildings in the Neubrücke Hospital area. The left half of Fig. 1 shows the system's terminal and central computer. The Honeywell 5600 system was installed during 1986-1987 during the renovation of the steam distribution lines at the facility. Although fairly reliable, the DTM again present some problems. The system uses Army-owned telephone cables that were formerly part of the German telephone system.

At the time of installation, funding was not adequate to extend the Honeywell 5600 system to the adjacent family housing complex. However, from subsequent projects, the switch cabinets and cabling necessary for the extension are already in place. Baumholder places medium to high priority on completing the connection of the family housing area to the Honeywell 5600 system.

\subsubsection{Messner/Miles}

The Messner/Miles UEMCS, with about 1500 points, serves 70 buildings at Nahbollenbach, Strassburg Kaserne, and Idar-Oberstein family housing. Figure 2 shows the control center for the system. Installed during 1988 at the three locations, the Messner/Miles system was designated "DDC" (direct digital control), implying at most a supervisory role for the central computer. The system also uses a wire-line DTM, though, unlike the Honeywell systems, no problems were reported associated with communications.

When installed, the Messner/Miles system had only general lightning protection. Subsequent substantial lightning damage, resulting in expensive parts replacement by the contractor, led to installation of a more extensive protection system. Examination of the Army guide specifications for UEMCSs should be made to see if tighter guidelines could possibly have avoided this problem. Also, at the time of the site visit, the system used two separate personal computers, dividing the input from the three island substations. However, they were expected to be replaced by a single computer within the year (1991).

\subsubsection{Landis \& Gyr}

The Landis \& Gyr demand-limiting UEMCS was installed at Baumholder during 1987, but only used in this mode since 1989 . The system has an additional start/stop function that can be based on an internal clock or triggered by an external source, such as a time clock or photocell. Initially only this start/stop function was exercised in controlling exterior lighting via a central photocell. In 
1989, demand limiting began using a ripple-control communication system over existing cabling to individual buildings. The system is currently able to limit electrical consumption of night heat storage units, electric radiators, transformer station heat, hot water generators, exterior lighting, and clothes dryers in family housing. Expansion of the system's control is ongoing; capacity is far from fully utilized and additional consumers are easily identified. Electric demand charges are DM 200 per $\mathrm{kW}$ based on the average of the two highest 15 -minute peaks anruually. Though duty cycling is possible with the system, none is implemented because sufficient load is not yet connected to the system. The contract with the electric supplier includes a peak demand ceiling, but the community seldom pays any associated penalty. The possibility of negotiating a lower ceiling price for improved rates may exist, if not immediately, certainly as more load is attached to demand limiting.

\subsection{SYSTEM MAINTENANCE}

Most UEMCS maintenance is attempted in-house with only major repairs, reprogramming, and upgrades contracted out. At the time of the site visit, local controllers were being repaired at a test bench that permitted simulation of field conditions. The community currently has three mechanics dedicated to the systems repair, with one additional person in training.

Problems are associated with the need to contract out major repairs. Contracts can take 6 to 12 months to negotiate and effect the repairs. This can be particularly troublesome for the Honeywell 1000 system, because it has no local control. In addition, software or hardware incompatibility can force the need for sole-source contracts. A comparison of maintenance experiences of Baumholder and Heidelberg may be beneficial. Heidelberg uses a similar as-needed repair contract ("Indefinite Delivery Type"), but experiences less difficulty with maintenance.

\subsection{FUTURE PLANS}

The potential for expansion of the current UEMCSs at the Baumholder military community is extensive. Numerous opportunities are recognized by the present utilities personnel. Those already mentioned in discussions held will be listed below in approximate order of indicated practicality or desirability.

- The Baumholder installation currently has the ability to meter total electric load at only a single metering point. Plans are under way to purchase equipment to allow additional submetering. This will assist in identifying future potential areas for conservation and problems that may currently exist.

- Expansion of demand limiting using the Landis \& Gyr system, which has already been mentioned, is ongoing. Field units for the ripple-control system cost only DM 150-200 each, making such expansion relatively inexpensive.

- The saturation and potential unreliability of the Honeywell 1000 system's CPU has fostered consideration of its replacement or its extension using excess capacity of the Honeywell 5600 computer. 
- Consolidation of individual small, older heating plants into a single, higher efficiency, normally gas-fired plant to service the same area has been found cost-effective. Such a consolidation is planned for the Quarter Master (QM) area of Baumholder. During the construction of the associated distribution system, communication cables for a UEMCS can be laid at less cost than if performed separately. The potential for incorporating additional facilities (a hospital and Wetzel and Smith family housing) either in the vicinity of the QM area or along a similar route from it to the UEMCS central station is also possible.

- The extension of the Honeywell 5600 UEMCS servicing the Neubrücke Hospital to the associated family housing area, though not planned, is being considered. Having the necessary switch cabinets and cabling already in place lessens the cost of the work.

- Connection of the Hoppstädten airfield and water works to the current UEMCS is made more practical by having the communication lines from the Honeywell 5600 system of the Neubrücke Hospital facility running nearby. 


\section{EVALUATION OF PROJECT DOCUMENTATION}

On June 14, 1991, a letter of introduction and request for data was sent to the Baumholder Utilities Division personnel via USAREUR Headquarters. Timing of the request was poor in that many of the key energy personnel at Baumholder were on leave during the period preceding the authors' August site visit. During the month of July, USAREUR provided data base listings of characteristics for the four main UEMCSs operated at Baumholder, and Baumholder Utilities Division personnel sent a year's district heat consumption data for the community's major installations.

During the site visit in August 1991, Utilities Division personnel were most helpful in granting interviews and tours. Data on fuel consumption was gathered from several sources. Data on fossil fuel consumption was copied from actual inventory sheets. However, electric and district heat consumptions by installation could not be located by the time of the authors' departure.

Documentation on the installation of the individual UEMCS equipment was also to be obtained. However, documentation before 1985 was said to be unavailable, while directions were given for obtaining project specifications on the more recent systems installed. Whether the contacts were never able to be made or the information was not available is unclear, but such data was never obtained.

On October 31, 1991, after evaluating the data obtained during the site visit, a request for additional data was sent to Headquarters, USAREUR. A response to questions and partial fuel consumption data were received on December 24, 1991. Additional data were received from Baumholder Utilities Division personnel on March 18, 1992. However, significant voids still existed. On April 24, 1992, USAREUR Headquarters obtained and relayed to ORNL data from annual reports that covered the desired fuels and latter years of interest, but these data were for the entire community, not for individual installations. There data, together with the 1990 data by installation received from the Baumholder Utilities Division, form the basis of the analysis in this report.

The authors wish to thank personnel both at Baumholder and USAREUR Headquarters for the exhaustive and repeated attempts to supply data necessary for this report. The difficulty experienced in these attempts is the basis upon which one of the recommendations of this report is founded. 


\section{ASSESSMENT OF SITE AND PHYSICAL CONDITIONS}

The 222D BSB at Baumholder, Germany, consists of numerous installations located as far as 63 miles from the principal installation at Baumholder. Figure 3 shows the location of the majority of these installations in relation to the Facilities Engineering Office, in which the UEMCS control center is located. The larger installations comprise several facilities, each with its individual functions. The following is a brief listing of the installations comprising the Baumholder military community, with their major facilities:

- Baumholder, comprising Smith Barracks, a hospital, the QM area, family housing, Wetzel Kaserne and family housing, an airfield, a missile facility, and government rental properties (GRP);

- Idar-Oberstein, including the Strassburg Kaserne, family housing, and GRP;

- $\quad$ Hoppstädten airfield, sewage plant, and waterworks;

- $\quad$ Neubrücke hospital, family housing, and GRP;

- $\quad$ Birkenfeld family housing;

- $\quad$ Pfeffelbach waterworks;

- Missile sites at Balesfeld, $\underline{\text { Hisel, }}$ Hontheim, Reitscheid, and Welschbillig;

- Storage areas at Nahbollenbach and Winterhauch; and

- Communication stations at Erbeskopf and Teufelskopf.

Only five facilities currently have support from UEMCSs: the Smith Barracks within the Baumholder installation, the Strassburg Kaserne and Idar-Oberstein family housing, the Neubrücke hospital, and the storage area at Nahbollenbach. They will form the primary focus of this study, although the other facilities may be referred to with regard to potential expansion of the current UEMCS capabilities. Following is a discussion of the general physical conditions within the installations at least partially serviced by UEMCSs. Table 2 displays the history of major energyrelated projects at these five facilities currently having UEMCSs.

\subsection{BAUMHOLDER}

Before 1982, the facilities at Baumholder were primarily heated by six to eight large central coal- and oil-fired plants supplying low- or high-pressure steam or hot water. The family housing areas were heated by individual small coal-fired plants. During 1982 and 1983, the Army acquired an additional large coal plant for the family housing. It was also during this time that the Honeywell 1000 UEMCS was installed in troop billets and administrative buildings within the Smith Barracks facility (see Sect. 2.1.1). In 1987, a Landis \& Gyr UEMCS capable of performing on/off functions as well as demand limiting was installed (see Sect. 2.1.4). However, the system was used only for control of exterior lighting until 1989, when demand limiting was initiated. 


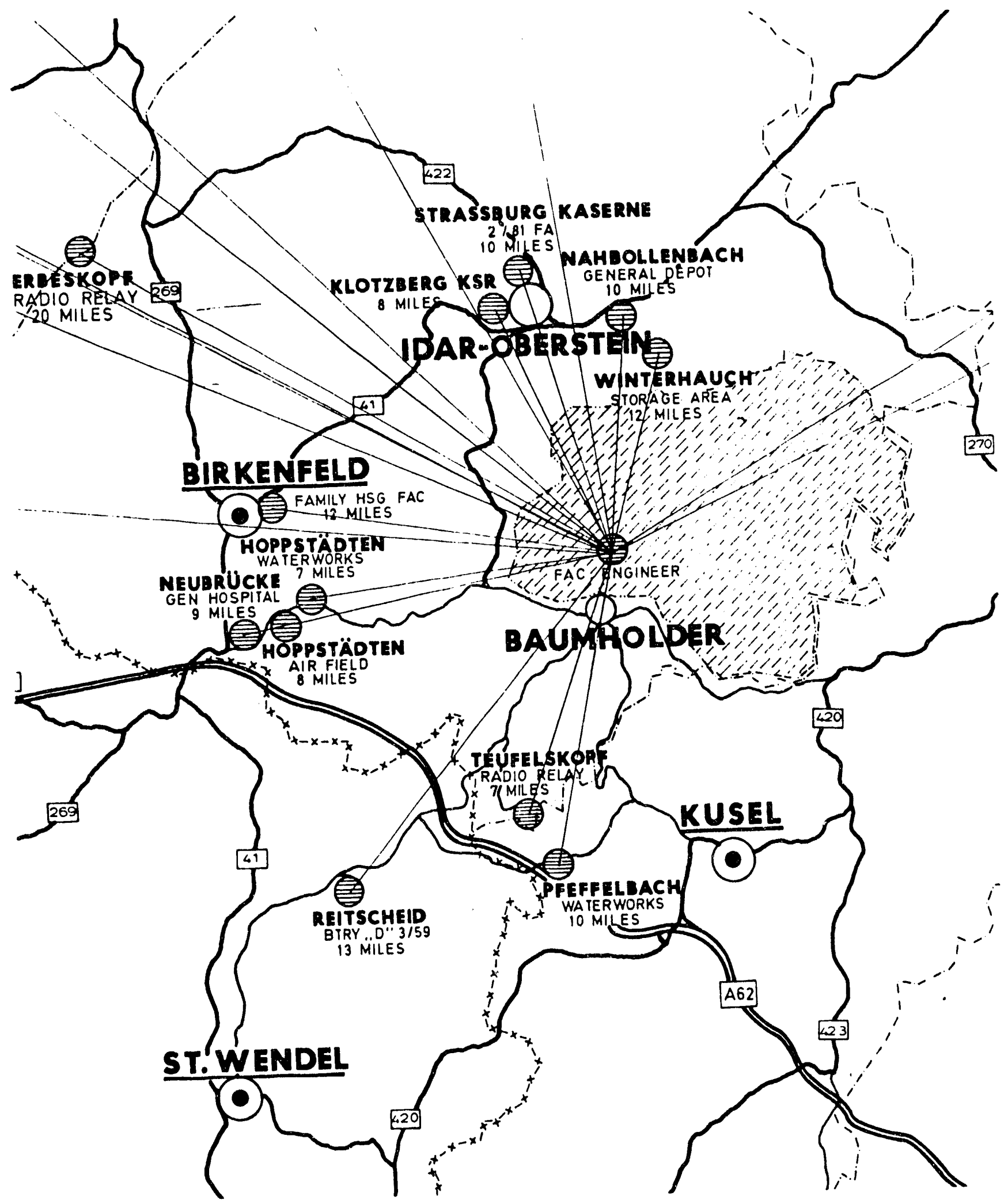

Fig. 3. Location of installations comprising the Baumholder military community. 
Table 2. Major energy-related projects at the Baumholder military community

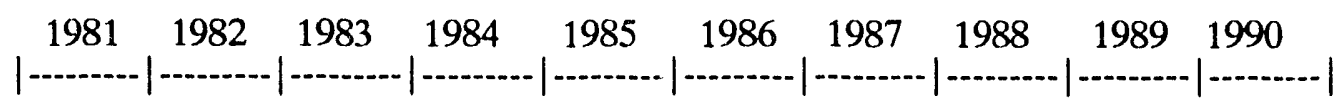

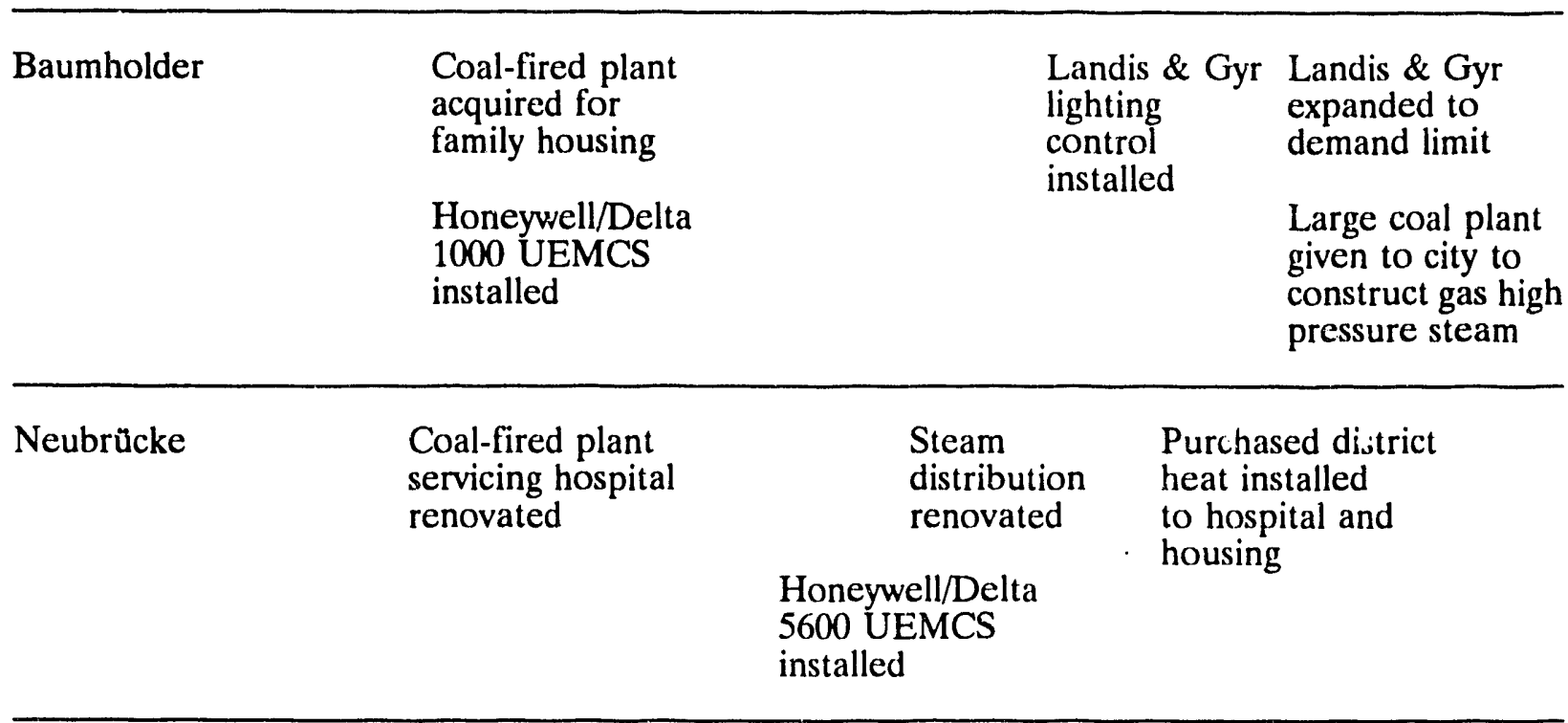

Nahbollenbach

Purchased district heat installed

Messner/Miles

UEMCS installed

Idar-Oberstein

Purchased district heat installed

Messner/Miles

UEMCS installed

\section{Strassburg \\ Kaserne}

Purchased district

heat installed

Messner/Miles

UEMCS installed

Messner/Miles

connected to

Baumholder

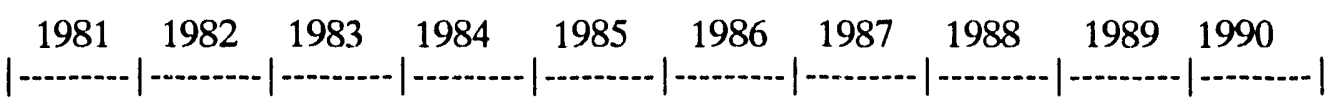


In 198 , the large coal-fired plant was given to the city for the purpose of constructing a new gas-fired high pressure steam boiler with sufficient capacity to heat all of the Baumholder installation. New steam lines from this plant were laid to the other major plants at the installation, where the boilers were replaced with converters, connecting the new district steam system to the existing individual building low-pressure steam or hot water (HW) heating lines.

Smith Barracks, the largest facility in the Baumholder military community with about 3.6 million square feet of building area, consists primarily of administrative buildings, barracks, and support facilities. The majority of the larger buildings are serviced by the Honeywell 1000 UEMCS, with demand limiting controlled by the Landis \& Gyr system. Most of the housing has 5-8 cm (2-3 in.) of expanded polystyrene board wall insulation. Barracks have less wall insulation, with some wall scgments, particularly of stone construction, not being amenable to insulating. More than half of the buildings in Smith Barracks have about $10 \mathrm{~cm}$ (4 in.) of ceiling insulation.

\subsection{NEUBRÜCKE}

Near the town of Birkenfeld, the Neubrücke installation comprises a 1000-bed hospital complex (now used for barracks and housing), support buildings, and a family housing complex. The total building area is about one million square feet. In 1982-1983 an Energy Conservation Investment Program project renovated the existing coal-fired low-pressure steam plant servicing the hospital facility, which modernized the coal delivery equipment. In 1986-1987 a second project renovated the steam distribution system and installed a Honeywell 5600 UEMCS to service approximately 30 buildings in the hospital facility (see Sect. 2.1.2).

In 1988-1989 the installation converted to district heat purchased from a local utility that has gas-fired boilers. Two heating substations convert the district steam into HW for distribution throughout the installation, including the associated family housing complex. The conversion was estimated to have 10 -year payback.

\subsection{NAHBOLLENBACH STORAGE AREA}

Outside the city of Idar-Oberstein, the Nahbollenbach storage area consists of many warehouses and adminisirative buildings, but no housing. Total building area for the installation is about 0.9 million square feet. Prior to a $1987-1988$ conversion, heat was supplied to the warchouses by either a central coal-fired HW plant or individual oil-fueled steam boilers. Other buildings were heated mainly by steam radiators. In 1987-1988 the installation adopted district heat, converting any steam heat to HW, including the radiators. In 1988-1989 a Messner/Miles UEMCS was installed (see Sect. 2.1.3). The central computer for the system was first left on site, but the UEMCS has since been connected by telephone line to Baumholder.

\subsection{IDAR-OBERSTEIN FAMILY HOUSING}

The Idar-Oberstein family housing complex is composed of 15 large housing units with associated support buildings, including a school and child care center. Prior to conversion, each of the housing units contained its own boiler that produced HW for heat. In 1988-1989 the facility was converted to district heat with a Messner/Miles UEMCS system. 


\subsection{STRASSBURG KASERNE}

Near the city of Idar-Oberstein and adjacent to the Idar-Oberstein family housing, the Strassburg Kaserne has 24 buildings including 4 barracks, a mess hall, a post exchange (PX), a bank, and a fast-food vendor, as well as additional family housing. The facility was heated with coal and oil-fired steam boilers until 1987-1988 when the conversion to gas-fired, HW district heat was accomplished. In 1988-1989 the Messner/Miles UEMCS was installed, with the centiai ciunputer located at the facility. In 1990 communication lines were made available to connect the system to the central computer in Baumholder. 


\section{ANALYSIS OF POTENTIAL ENERGY SAVINGS}

This section examines actual energ $/$ consumption in the Baumholder community. Historical data was available for only the community as a whole, making identification of UEMCS savings from individual installations or facilities difficult. However, energy consumptions by fuel type and installation were obtained for fiscal year 1990, allowing some analyses. An attempt is made to correlate observed trends with site improvements resulting from UEMCS and other conservation efforts.

Table 3 shows fuel consumption by year, from 1985 through 1990. The top part of the table is broken down by individual fuel type. The bottom portion of the table includes heating degree days (HDDs) and the building square footage as of the end of each year. The last three rows in the table compare (1) the annual total energy consumption per square foot building area, (2) the thermal energy consumed normalized for weather and building square footage, and (3) the electricity consumed per thousand square feet.

The total energy consumed increased $10 \%$ between 1985 and 1986, then decreased gradually a total of $20 \%$ to 1990 . The majority of the increase from 1985 to 1986 stems from the increasing thermal energy between these years. However, reductions in the thermal energy consumed from 1986 through $1990(25 \%)$ account for the majority of reduction in total energy used between these years. These trends can be seen more clearly by examining Fig. 4 .

The clearest trend in Fig. 4 is the impact of converting heating plants from coal and oil to HW district heating. In 1987, before converting to district heat, $1075 \mathrm{kMBtu}$ thermal energy was consumed. In comparison, in 1990, after conversion, only $852 \mathrm{kMBtu}$ were consumed, a $21 \%$ decrease in thermal energy consumption. However, the 1990 consumption uses the kMBtu of district heat consumed, not the kMBtu of the source fuel used to generate the district heat. It, therefore, does not include the losses associated with generating the energy, unlike the 1987 thermal consumption, produced from all fossil fuels. Thus, the $21 \%$ energy consumption decrease is actually considerably less, if the source fuel savings are considered. No information was available on the various plants producing the purchased district heat. However, if it is assumed they are about $85 \%$ efficient in converting the source fuel into delivered district heat, the $21 \%$ savings indicated becomes $10 \%$, still a significant reduction. Note, if the district heat plants had been co-generation plants, no reduction in energy savings because of to the district heating plant efficiencies would be applicable.

The normalized energy consumptions reflect the actual consumptions quite well. Normalized thermal energy consumption increases $9 \%$ from 1985 to 1986 , then decreases relatively uniformly a total of $21 \%$ from 1986 to 1990 . Figure 5 shows the normalized thermal consumption as well as the normalized total consumption. The increase in consumption from 1985 to 1986 is unexplained. During 1985 and 1986, the Honeywell 5600 UEMCS was installed at Neubrücke. Part of the decrease in thermal energy consumption seen between 1986 and 1987 may be because of this installation, because no other major energy conserving project was introduced during this same time period (see Table 2). Unfortunately, however, the installation of the Messner/Miles systems at Nahbollenbach, Idar-Oberstein, and Strassburg Kaserne occurred almost concurrently with the conversion to district heat, likely eclipsing the effect of this UEMCS. 


\begin{tabular}{|c|c|c|c|c|c|c|c|c|c|c|c|c|c|c|c|}
\hline $\begin{array}{l}8 \\
8 \\
2 \\
2\end{array}$ & 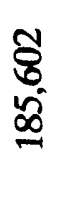 & & 0 & 0 & $\begin{array}{l}\infty \\
\infty \\
\sigma\end{array}$ & 尽 & $\begin{array}{l}\tilde{\sigma} \\
\tilde{\sigma} \\
\tilde{\sigma}\end{array}$ & 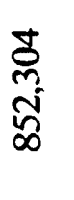 & 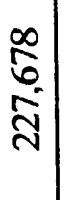 & $\begin{array}{l}\sigma \\
\delta \\
\sigma \\
\sigma \\
\delta \\
=\end{array}$ & $\frac{S^{\circ}}{\sigma^{\circ}}$ & 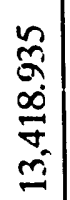 & $\begin{array}{l}\infty \\
\stackrel{\infty}{0} \\
\stackrel{\infty}{0}\end{array}$ & 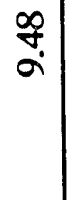 & $\begin{array}{l}\hat{a} \\
0 \\
-1\end{array}$ \\
\hline $\begin{array}{l}\mathscr{8} \\
\text { g } \\
z \\
2\end{array}$ & 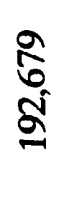 & 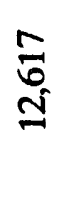 & 0 & $\stackrel{n}{\tilde{z}}$ & 客 & ฟ & 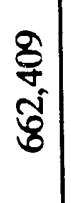 & $\begin{array}{l}\mathscr{V} \\
\text { ने } \\
\delta \\
\mathscr{\infty}\end{array}$ & 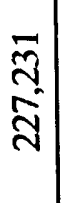 & $\begin{array}{l}8 \\
8 \\
5 \\
5 \\
-i\end{array}$ & $\frac{\sqrt{n}}{6}$ & 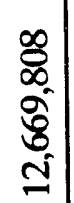 & $\frac{\sigma}{\dot{\infty}}$ & ָ̊ ִָ & $\begin{array}{l}\sigma \\
\sigma \\
\end{array}$ \\
\hline 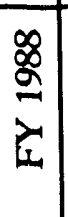 & $\begin{array}{l}\bar{\nwarrow} \\
\text { స్ } \\
\text { ฟै }\end{array}$ & $\begin{array}{l}\bar{~} \\
\text { ภે }\end{array}$ & $\frac{m}{\underset{z}{n}}$ & $\begin{array}{l}\vec{N} \\
\tilde{\infty}\end{array}$ & $\stackrel{n}{m}$ & $\stackrel{\sigma}{\frac{\sigma}{\sigma}}$ & 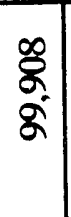 & 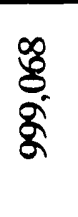 & $\begin{array}{l}\bar{n} \\
\tilde{n} \\
\stackrel{N}{N} \\
\stackrel{n}{*}\end{array}$ & 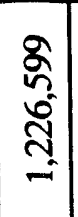 & $\frac{F}{ت}$ & $\begin{array}{l}\hat{\infty} \\
n \\
\tilde{\delta} \\
n \\
\end{array}$ & $\frac{N}{\infty}$ & $\stackrel{\infty}{\rightleftarrows}$ & $\begin{array}{l}\text { ণ్ } \\
\infty\end{array}$ \\
\hline$\frac{5}{2}$ & 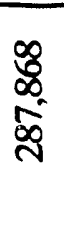 & $\begin{array}{l}\stackrel{m}{0} \\
\frac{n}{n}\end{array}$ & 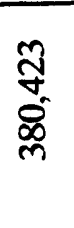 & 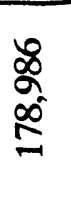 & $\underset{\sim}{\stackrel{m}{\forall}}$ & $\underset{\mathcal{S}}{\mathcal{S}}$ & 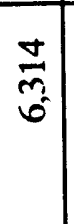 & $\begin{array}{l}\frac{9}{5} \\
\text { ñ } \\
5 \\
0\end{array}$ & $\begin{array}{l}\frac{o}{T} \\
\hat{\sigma}^{n} \\
\vec{N}\end{array}$ & 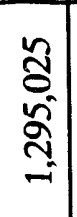 & $\begin{array}{l}\mathscr{8} \\
\dot{\sigma}\end{array}$ & 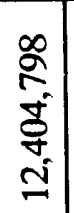 & $\begin{array}{l}\text { P } \\
\dot{+} \\
\stackrel{-}{*}\end{array}$ & 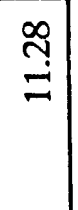 & $\underset{I}{\Xi}$ \\
\hline 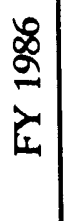 & $\begin{array}{l}n \\
\infty \\
\infty \\
\infty \\
m\end{array}$ & 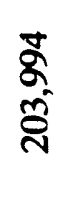 & 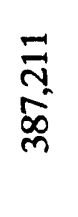 & $\begin{array}{l}5 \hat{\sigma} \\
\text { ઠ̊ }\end{array}$ & $\begin{array}{l}\text { 守 } \\
\text { ñ }\end{array}$ & ్ㅗ & $\frac{\delta}{m}$ & 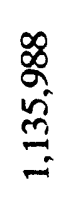 & 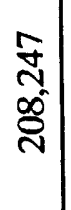 & $\begin{array}{l}n \\
\tilde{n} \\
j \\
\tilde{j} \\
\tilde{m}\end{array}$ & $\underset{⿱ 乛}{\stackrel{N}{N}}$ & 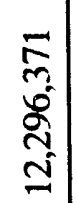 & 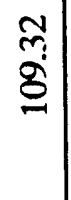 & $\stackrel{\text { \&̊ }}{=}$ & 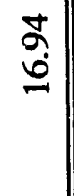 \\
\hline$\frac{\mathscr{\infty}}{2}$ & 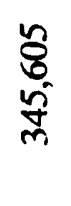 & 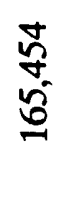 & $\begin{array}{l}\hat{8} \\
\stackrel{0}{m}\end{array}$ & $\begin{array}{l}n \\
\\
\infty \\
\approx\end{array}$ & $\begin{array}{l}\text { \$ } \\
\stackrel{2}{ } \\
\forall\end{array}$ & $\frac{\partial}{\vec{\gamma}}$ & $\begin{array}{l}\mathcal{B} \\
\text { m. } \\
m\end{array}$ & 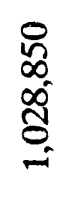 & $\begin{array}{l}\frac{9}{5} \\
\stackrel{5}{5}\end{array}$ & 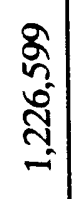 & $\frac{n}{6}$ & 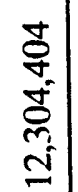 & $\begin{array}{l}8 \\
8 \\
8\end{array}$ & 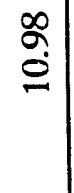 & $\begin{array}{l}\sigma \\
0 \\
\underline{0}\end{array}$ \\
\hline 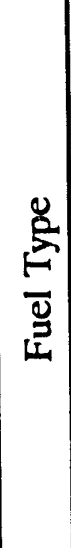 & $\begin{array}{l}\bar{\sigma} \\
\bar{d} \\
己 \\
N \\
\dot{0} \\
z\end{array}$ & 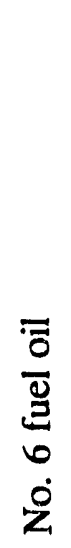 & 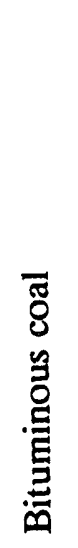 & 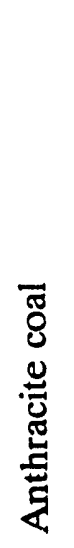 & 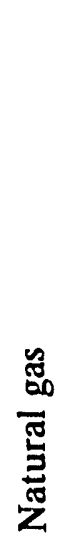 & 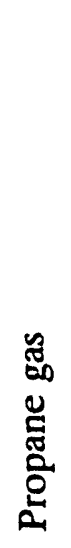 & 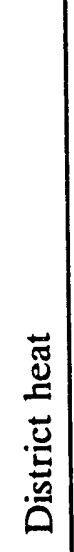 & 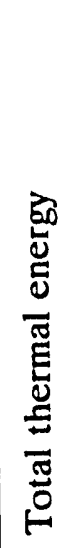 & 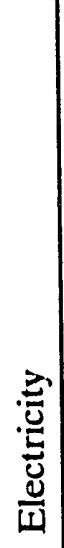 & 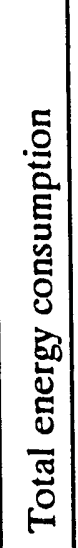 & 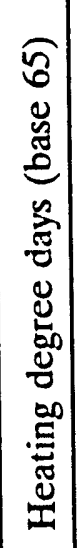 & 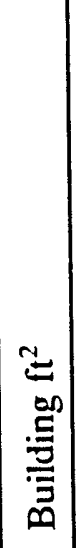 & 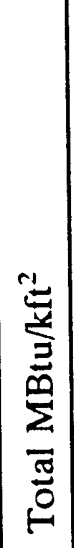 & 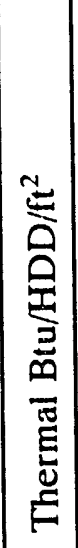 & 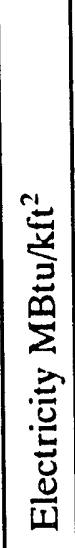 \\
\hline
\end{tabular}




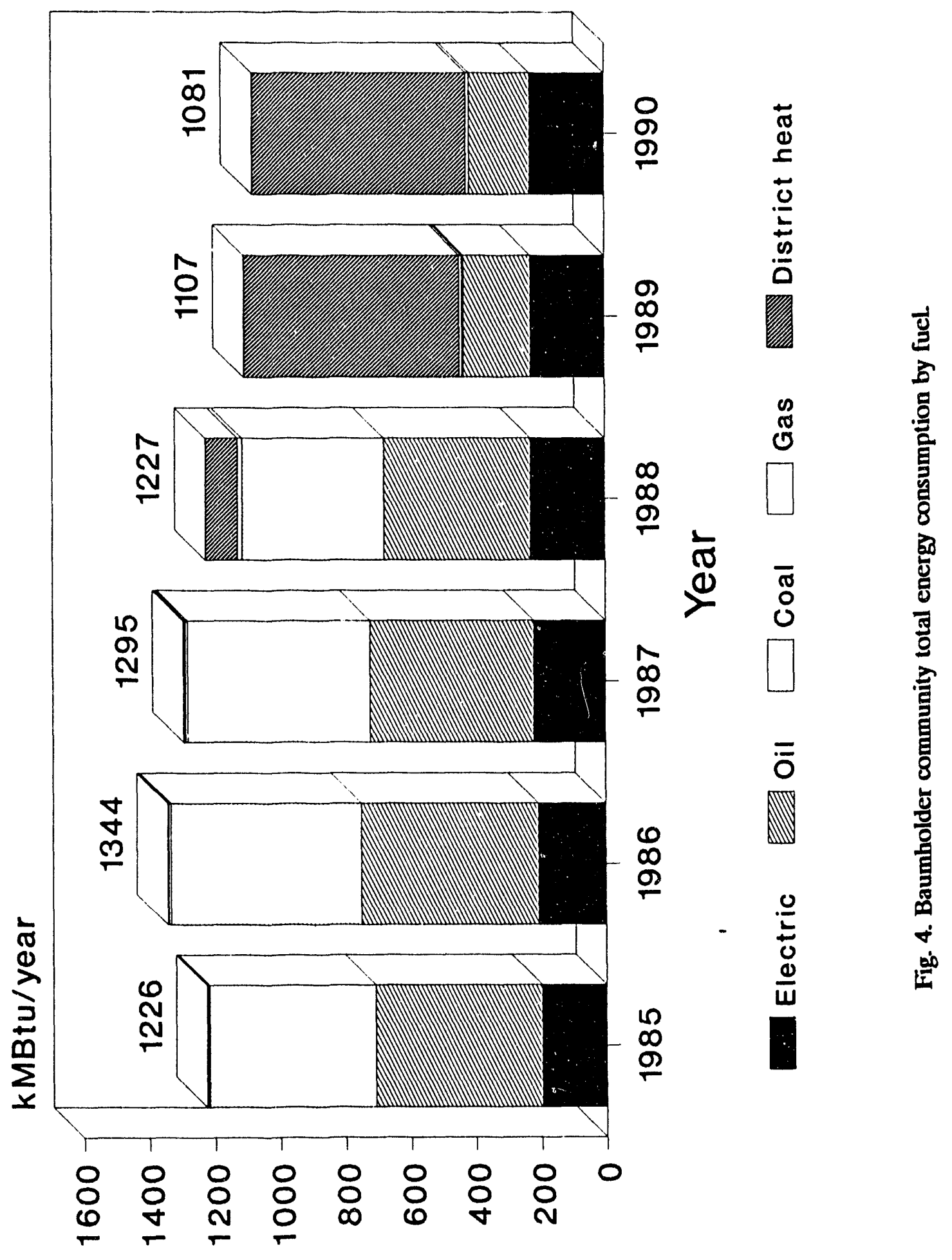




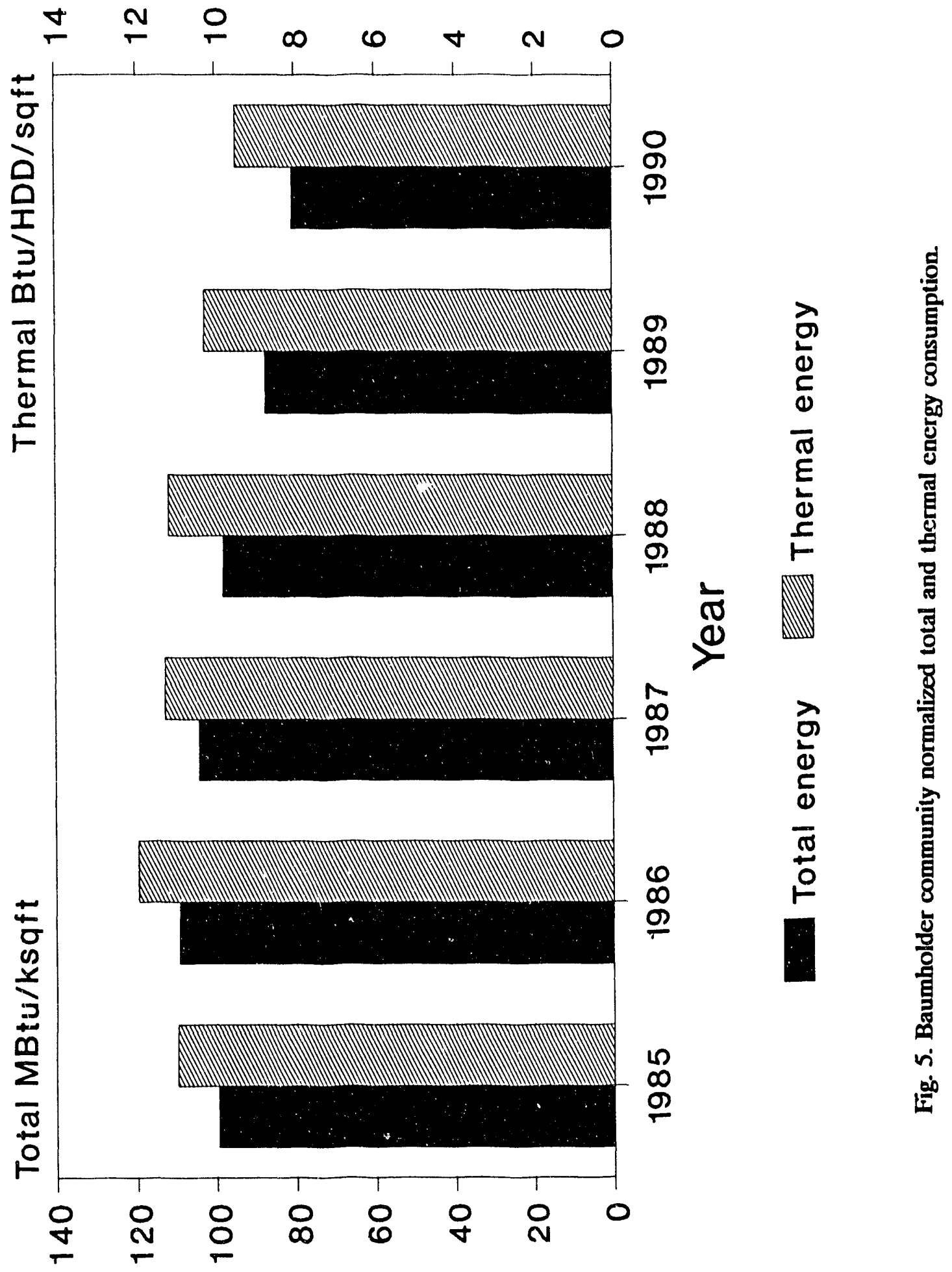


The installation of the Honeywell 1000 UEMCS at Baumholder occurred before 1985, the earliest year for which consumption data is available, thus preventing any examination of its effect on energy usage. This is unfortunate since Baumholder is the largest energy-consuming installation at the community, thus offering the greatest potential for seeing the effect of a UEMCS.

Normalized electrical energy consumption (MBtu/kft ${ }^{2}$ ) increased $13 \%$ between 1985 and 1988 , then decreased $7 \%$ from 1988 to 1990 . It is unclear why the electrical consumption trend reversed. The Landis \& Gyr load control system, which began operation in 1989, would reduce electrical demand, but generally have little or no effect on energy consumption. It is also unlikely that the exterior iighting control, implemented in 1987, would have sufficient effect to abate the increasing consumption trend seen from 1985 through 1988 . There is the possibility that with the conversion to district heat, more efficient pumps and other electrical equipment were installed, reducing the consumption, or thet the total community building area did not accurately reflect the utilization, and, therefore, the electrical consumption.

Figure 6 plots the monihly energy usage in kMBtu. Figure 7 reflects the same basic data, cxcept monthly energy usage has been normalized by building square footage. As expected, these plots reveal decreased energy usage after coal and oil plant conversion to district heat and implementation of the UEMCS systems.

Table 4 tabulates the fossil fuel and electrical energy consumptions during 1990 for the 17 installations comprising the Baumholder community. Figures 8 and 9 are plots based on the information in Table 4, Fig. 8 contrasting the thermal energy consumption and Fig. 9 the electrical consumption at each of the sites for which billing data were available. Data for the table were pieced together from various sources and is not completely consistent or correct. The little or no electrical consumption indicated for Birkenfeld, leased housing, and Idar-Oberstein is likely incorrect. The absence of thermal consumption at Pfeffelbach and Winterhauch is suspect. Idar-Oberstein's thermal consumption is also likely incorrect, as indicated by the unusually low $\mathrm{Btu} / \mathrm{HDD} / \mathrm{ft}^{2}$ that the value predicts. The total square footage taken from the sum of the individual estimates of area differs from the annual value reported in Table 3 for 1990 , but resembles more closely the value given there for 1989. This may merely reflect a difference in when during the year the figures were computed.

Baumholder accounts for $71 \%$ of the steam and hot water and $52 \%$ of the oil usage. Clearly, energy conservation measures should be concentrated within Baumholder. Similarly, Baumholder is the prominent electrical energy consumer in the community, accounting for $64 \%$ of the electrical cnergy. Baumholder is unquestionably the largest energy consumer in the community, accounting for nearly $66 \%$ of the total energy consumed.

Normalized thermal consumption $\left(\mathrm{Btu} / \mathrm{HDD} / \mathrm{ft}^{2}\right)$ for Baumholder, Neubrücke, and Nahbollenbach are consistent with facilities having well managed UEMCS controls. The 14.9 $\mathrm{Btu} / \mathrm{HDD} / \mathrm{ft}^{2}$ consumption for the Strassburg Kaserne is somewhat higher, though still not excessive. The missile sites (Balesfeld, Hisel, Hontheim, Reitscheid, and Welschbillig) have consistently higher normalized thermal consumption than other facilities. Though measures might exist that could decrease their consumption levels, individually the amount of energy consumed compared to the total for the community is small, making justification of excessive effort to reduce unwarranted. Nevertheless, examination of energy use practices at these sites would likely identify the reason for the high normalized consumption and if any inexpensive means of reduction are possible. 


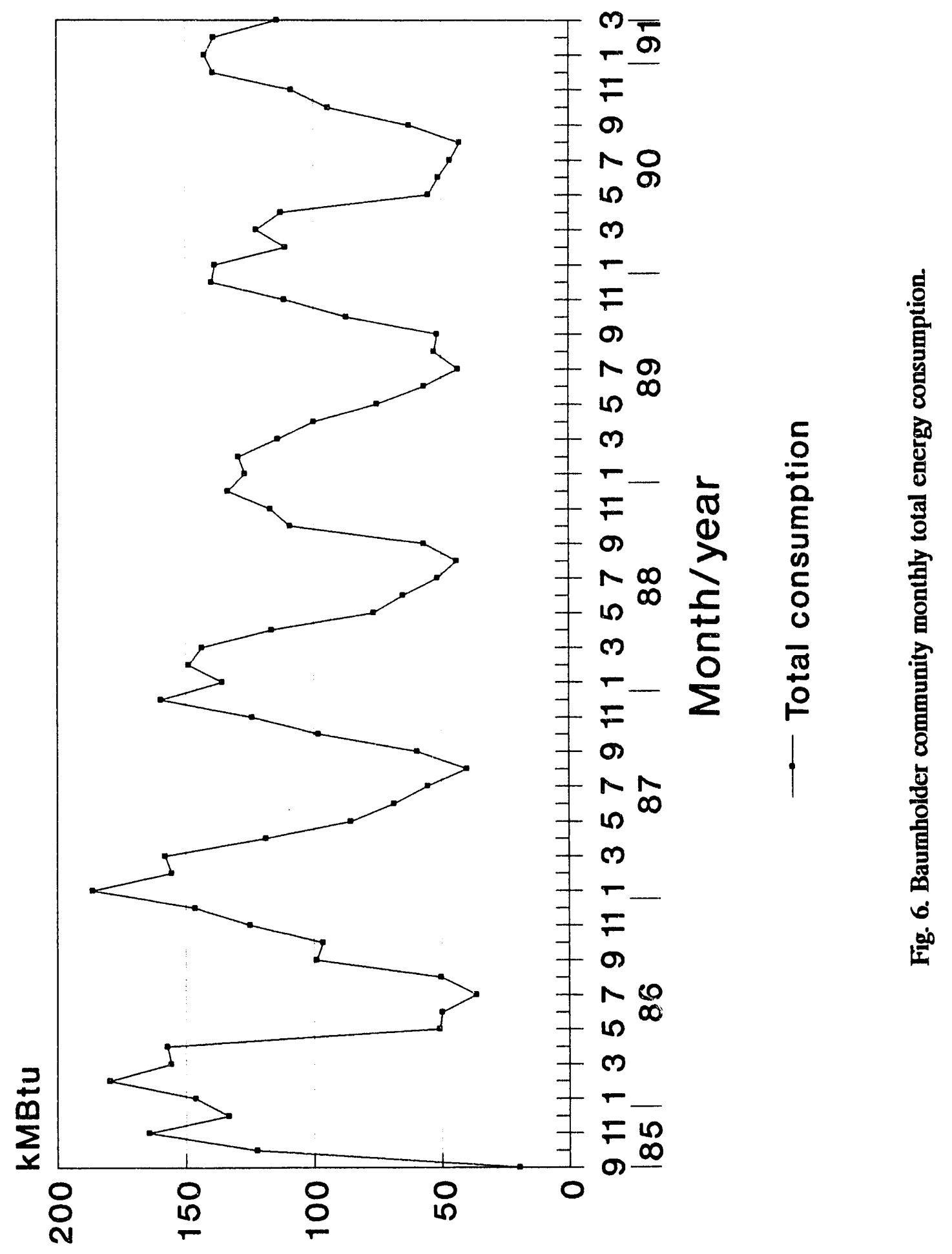




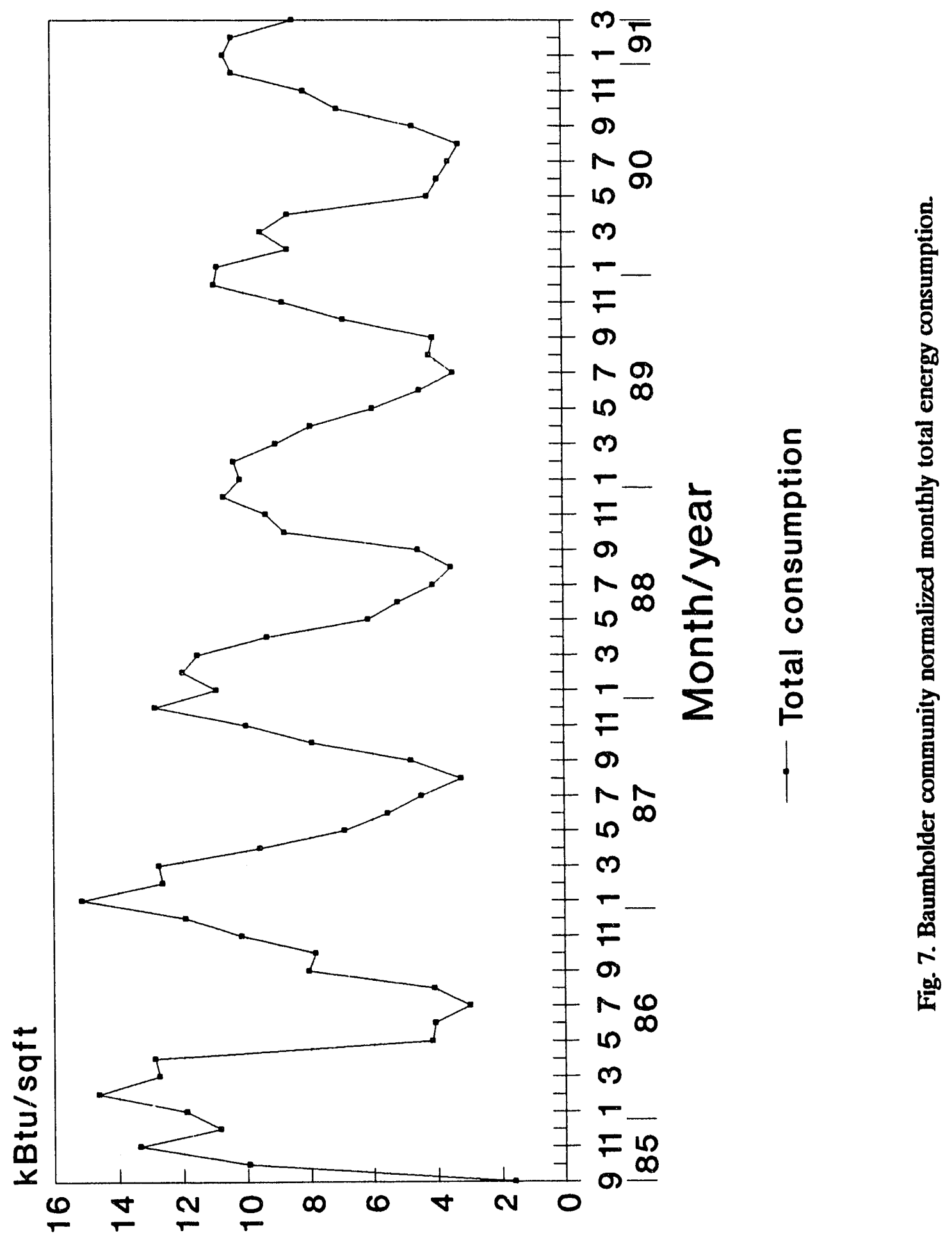




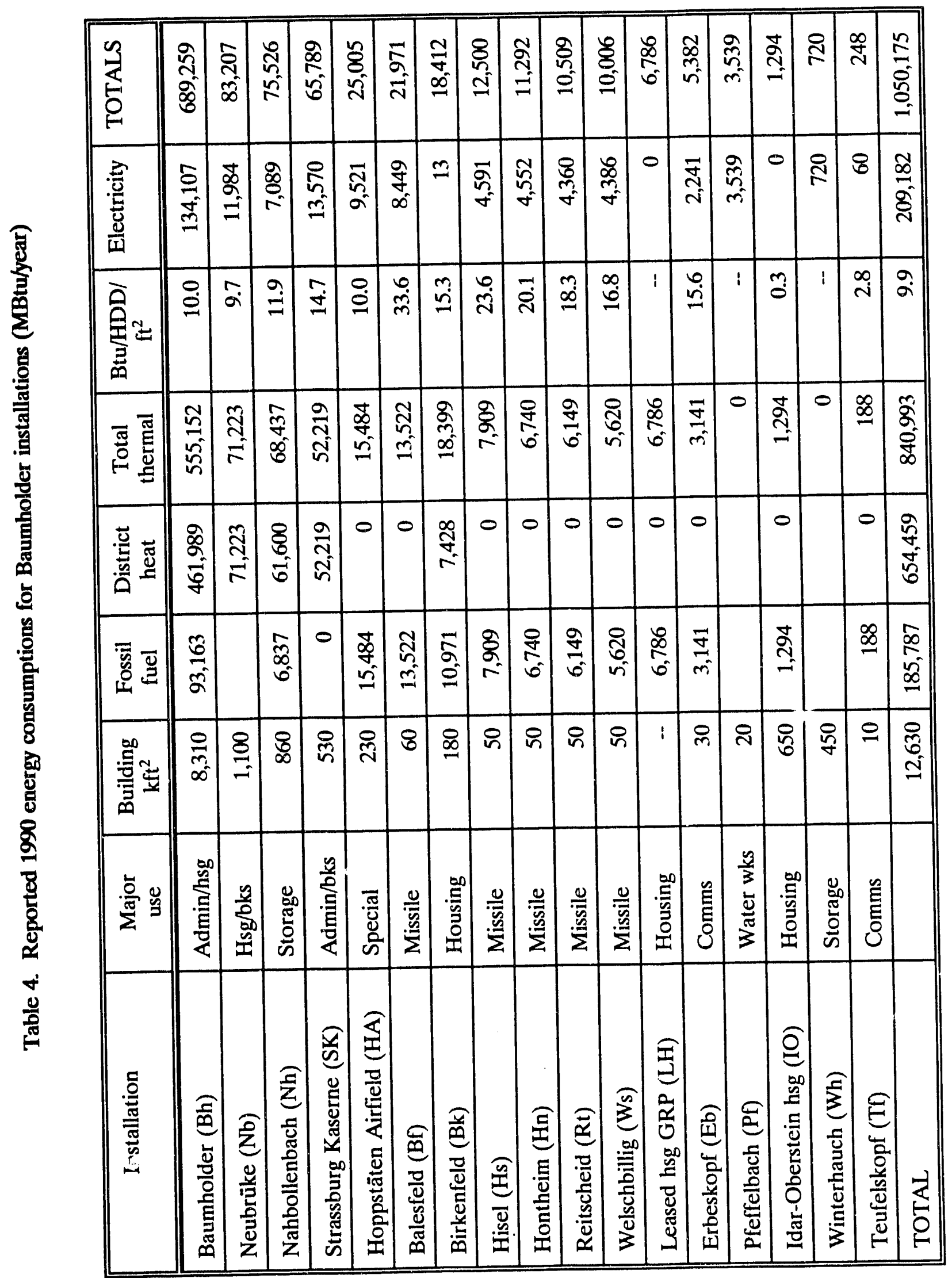




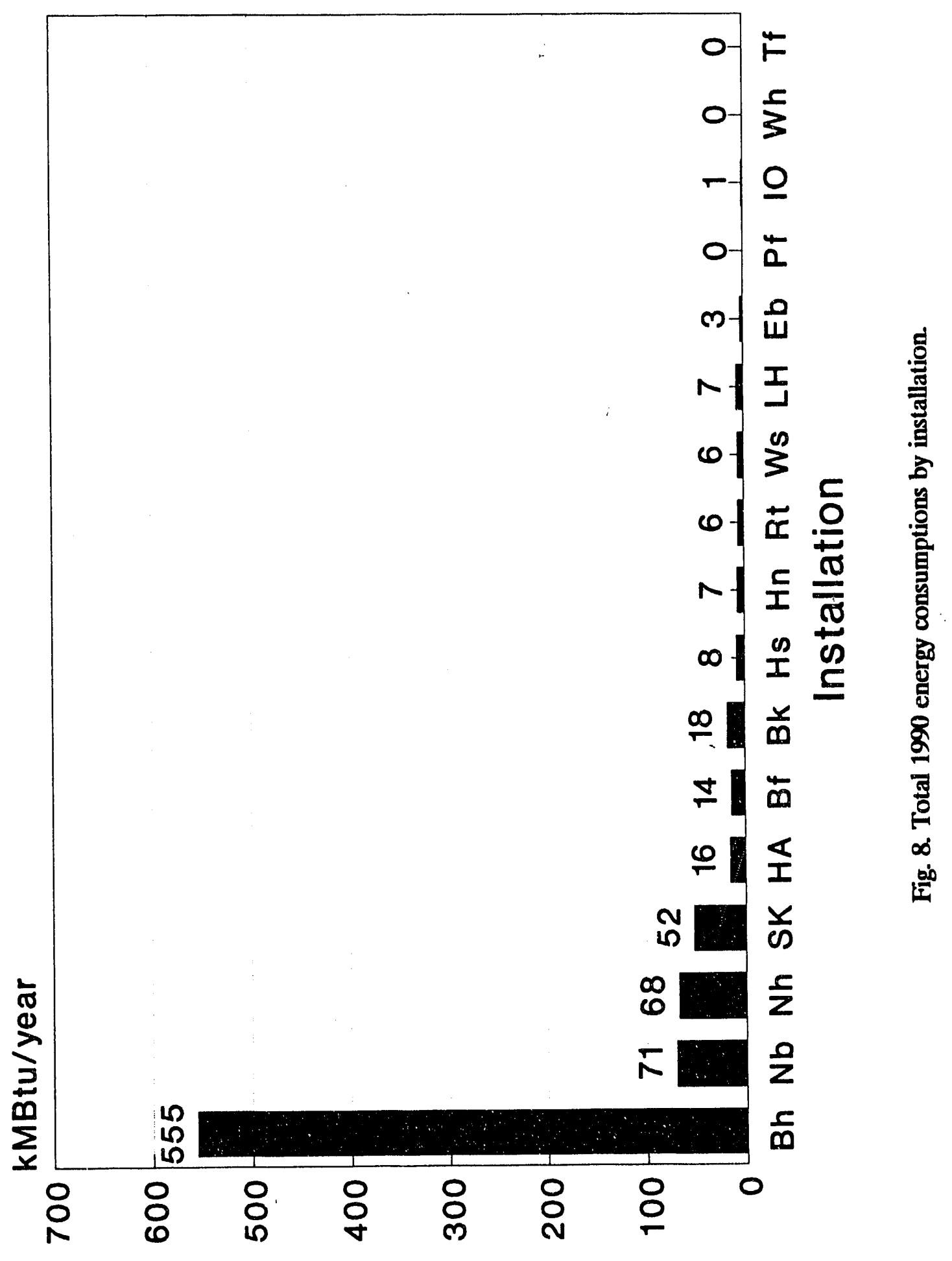




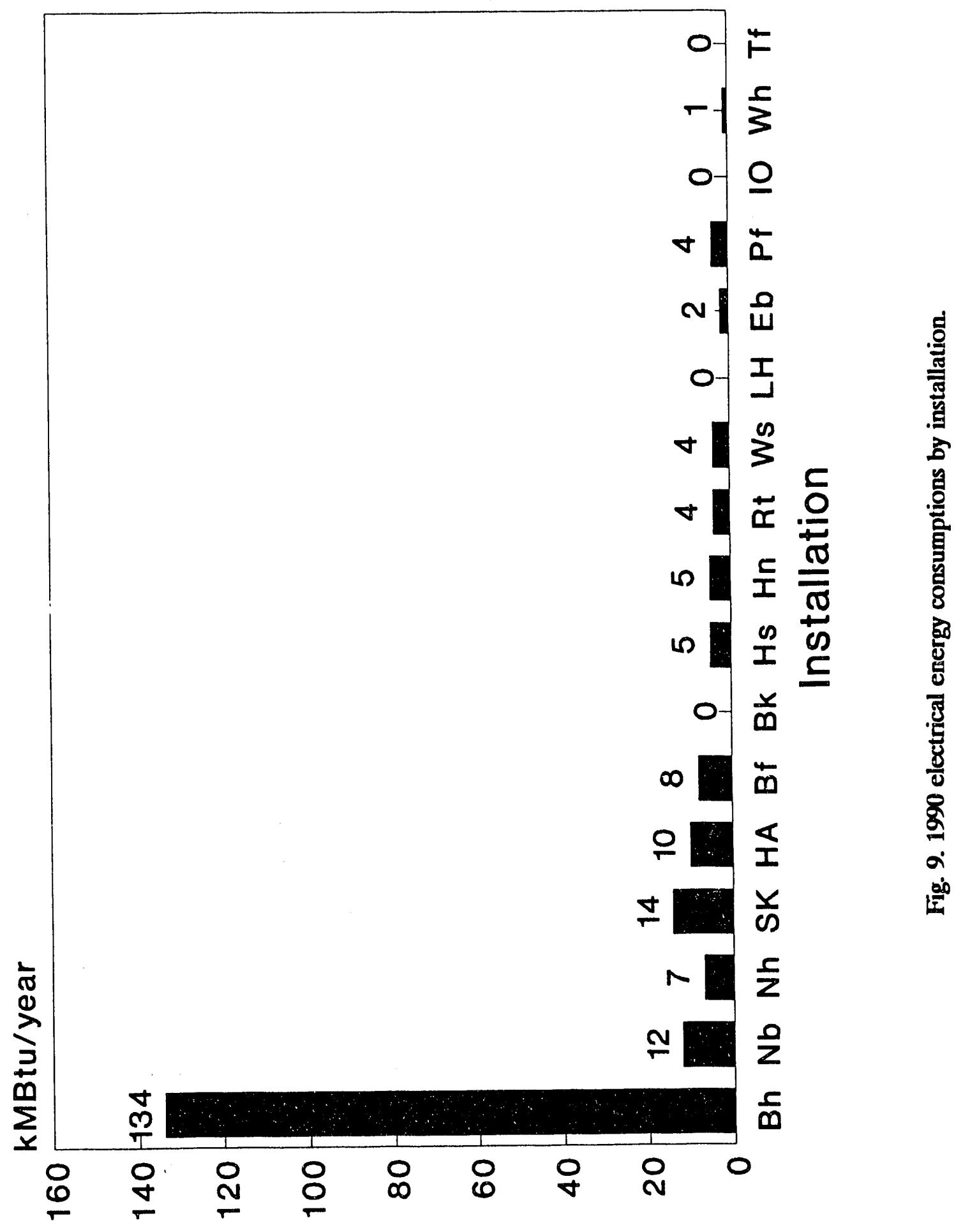


The 1990 normalized thermal energy consumption for the entire community (Btu/HDD/ $\mathrm{ft}^{2}$ ), reported in Table 4, and the normalized total consumption (Btu/kft ${ }^{2}$ ), obtained by dividing Table 4's total consumption by the total area, is compared in Table 5 with analogous values computed for other communities studied in this project. Though higher than at the other two facilities reported, Baumholder's normalized consumptions are not inordinately high. As a larger fraction of Smith Barracks is connected to the UEMCS, the values will likely decrease to compare even more with those seen elsewhere. It must be noted that Heidelberg's 1989 normalized thermal energy consumption was 9.27 , showing the potential degree of variability of the parameters.

Table 5. Comparison of 1990 community normalized energy consumptions

\begin{tabular}{|c|c|c||}
\hline Community & $\begin{array}{c}\text { Total energy } \\
\text { MBtu/kft }\end{array}$ & $\begin{array}{c}\text { Thermal energy } \\
\text { Btu/HDD/ft }\end{array}$ \\
\hline \hline Heidelberg & 58.0 & 7.72 \\
\hline Pirmasens & 77.5 & 9.32 \\
\hline Baumholder & 83.2 & 9.90 \\
\hline
\end{tabular}

The Utilities Division's plans for expansion of the UEMCS (see Sect. 2.3) are centered about the Baumholder, Neubrücke, and Hoppstådten installations. Baumholder and Neubrücke are the two highest energy consumers in the community, and Hoppstădten is the highest consumer with no UEMCS equipment (see Fig. 8). Thus, their selection appears prudent. However, if data received has been interpreted correctly, Hoppstådten already has a relatively low normalized consumption at $10.0 \mathrm{Btu} / \mathrm{HDD} / \mathrm{ft}^{2}$.

Data for the Idar-Oberstein family housing are obviously incorrect. Utilities personnel may be able to locate the correct data, and, with additional data in Table 4, determine normalized consumption. Note that insufficient historical data was available to determine the trend of normalized thermal consumption from year-to-year for the individual installations.

Scanning the electrical billing data revealed some data regarding power factor compensation. The majority of the sites had power factors of $98 \%$ or greater, representing excellent compensation. High power factors minimize electrical losses. The three largest electrical energy consumers, Baumholder, Strassburg, and Neubrücke have $95 \%$ power factors. These power factors are adequate, making additional compensation unnecessary.

Continued expansion of the electric load connected to the UEMCS's demand limiting should be pursued. Though not necessarily an energy saving measure, cost reductions are possible either through reduced monthly demand charges or possibly lower rates resulting from a lower contracted peak ceiling. Engineering studies should be initiated that will determine how much additional load control can be effectively implemented at Baumholder. 


\section{UTILITIES AND ENERGY MONITORING AND CONTROL SYSTEM APPLICATIONS AND THEIR SAVINGS}

Energy conservation applications implemented by the UEMCSs at Baumholder are listed in Table 6 and discussed individually in Sect. 6.1. Section, 6.2 summarizes the potential savings attributable to each application and compares these savings with the historical trends discussed in Sect. 5. However, few conclusions can be reached because of the lack of annual consumption data for the individual installations and the absence of information regarding the extent to which the applications were implemented by local controllers before introduction of the UEMCSs.

\subsection{APPLICATION DESCRIPTION}

The Baumholder military community implements many standard UEMCS applications. Their description and operational characteristics, together with means of estimating potential associated energy savings, are described below.

\subsubsection{Day/Night Setback-Optimum Start/Stop}

The day/night setback program reduces energy consumption in buildings by reducing the set point temperature during unoccupied hours or hours when occupants would normally be sleeping. Family housing at Baumholder experiences a $3-5^{\circ} \mathrm{C}\left(5-9^{\circ} \mathrm{F}\right)$ setback between the hours of 10:00 p.m. and 5:00 a.m. Family housing not connected to a UEMCS may still have day/night setback imposed by local controllers, but no straightforward means of adjusting the setback temperature or unoccupied period exists.

Most administrative spaces under UEMCS control use an optimum start/stop application in which heating equipment may be set back or totally shut down during unoccupied hours. Under optimum start/stop, equipment is automatically controlled based on desired space temperatures (occupied and unoccupied), occupancy schedule, outside air temperature, heating system capacity, and building thermal inertia. Administrative spaces at Baumholder are normally assumed unoccupied between 5:00 p.m. and 5:00 a.m.

Estimates of energy savings resulting from operation of day/night setback and optimum start/stop applications vary widely, particularly in new of the diversity in setback temperatures and number of unoccupied hours/week assumed. Heidelberg assumes a $16 \%$ savings in family housing and a 27\% savings in administrative spaces utilizing optimum start/stop (Broders and McConnell 1991). Other sources would suggest less potential savings, ranging from 3 to $8 \%$ in housing and 11 to $19 \%$ for administrative spaces (NBSIR 1984, "Good News..." 1991, NCEL 1982). For the purposes of this study, percent savings between these extremes will be used, namely, $8 \%$ for family housing and $19 \%$ for administrative spaces under optimum start/stop. The latter approximation uses Baumholder's estimate that optimum start/stop saves an additional 5\% over normal night setback.

Facilities personnel indicated that approximately $80 \%$ of the Smith Barracks facility was attached to the UEMCS. In addition, Smith Barracks constitutes only $43 \%$ of the building square foot floor area of the entire Baumholder installation. Therefore, in estimating the above, and subsequent savings, only $34 \%$ of the total Baumholder installation energy consumption is assumed controlled by the UEMCS 
Table 6. Conservation applications in effect at Baumholder

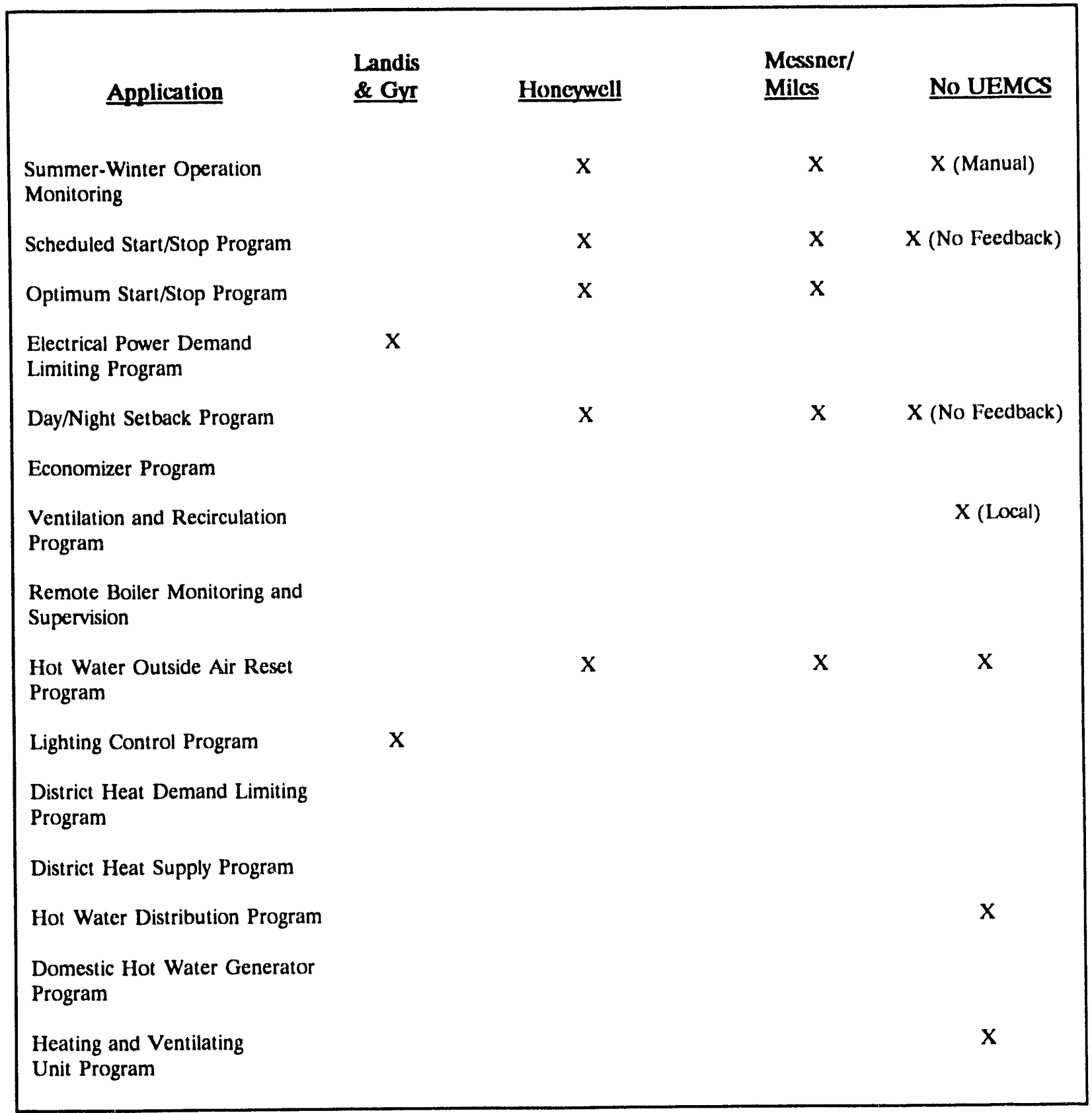


In estimating the savings attributable to the UEMCS, it is difficult or impossible to determine what portion of the above savings would have been accomplished by the old local controllers having similar capabilities. Baumholder personnel indicated that while most all facilities not connected to the UEMCSs still perform night setback, few to none are able to implement optimum start/stop. However, doubt was also expressed regarding the reliability of the old controllers and the concern that without the UEMCS, no feedback was provided to insure proper operation. Nevertheless, the savings estimated here is possibly greater than that which could actually be credited to the UEMCS and expected to be seen in a historical trend analysis of the energy consumption.

\subsubsection{Outside Air Reset}

The hot-water outside-air-reset program adjusts the heating water temperature from the district heat to reflect decreased heating requirements during warmer weather, as indicated by the outside air temperature. Estimates of savings attributable to the hot-water outside-air-reset application are taken from algorithms published by the Navy Civil Engineering Laboratory (NCEL 1982). The values are based on reported district heat capacities for each installation. Similar to the night setback application, the outside-air-reset program was performed locally by controllers prior to installation of the UEMCSs at Baumholder. Thus the savings projected for the application may not be totally attributed to the UEMCS or noticeable in a trend analysis of consumption.

\subsubsection{Lighting Control Program}

The Landis \& Gyr UEMCS is used for control of exterior lighting via a central facility photocell. The photocell tells the system when lights are needed and those attached are then turned on by signals transmitted through the system's ripple control communication network. Security conditions place some restrictions on the extensiveness of the application. Estimates of energy savings are difficult to make. Submetered electrical data for exterior lighting was obtained for 1989 and 1990, but not for years before the installation of the system, in 1987. The submetered data indicate a total 1990 electrical consumption for the entire community for exterior lights of 2251 MWh, about 3\% of the total electric energy used for that year. Savings from use of the Baumholder UEMCS driven by the photocell for lighting control is likely less than one fifth of this amount, or about $450 \mathrm{MWh}$ (1540 MBtu).

\subsubsection{Demand Limiting}

Baumholder's Landis \& Gyr demand limiting UEMCS with ripple control has a total of 869 $\mathrm{kW}$ attached, compared to 1990 's peak demand of $6980 \mathrm{~kW}$, or $12 \%$. No data are available regarding the actual annual peak reductions that have occurred. Heidelberg (Broders and McConnell 1991) reports an $8.63 \%$ peak reduction, certainly within the capability of Baumholder's $12 \%$. If Heidelberg's factor is applied to Baumholder's 1990 peak, a demand reduction of $600 \mathrm{~kW}$ results. At a rate of $200 \mathrm{DM} / \mathrm{year}$, the estimated monetary savings is $120 \mathrm{kDM} / \mathrm{year}$. The electrical chief indicated that the electrical load attached to the system could likely yet be doubled, suggesting an increased savings in the future. 


\subsubsection{Summer/Winter Operation Monitoring (Switchover)}

The summer/winter operation monitoring program helps accomplish summer/winter switchover. Generally, it provides the means to change operating parameters, alarm limits, and start/stop schedules for each electrical and mechanical system attached to the UEMCS. The program can be used to efficiently limit the heating season, or simply avoid inadvertent heating during summer or swing seasons. The Baumholder command has chosen the latter approach in attempts to insure the comfort of its personnel. Thus, substantial energy savings is not likely to result. However, the measure does provide manpower savings by eliminating utility personnel's need to individually visit equipment sites to make seasonal adjustments or to shut off mechanical systems. Nevertheless, Table 7 shows estimates of savings that would result from reducing the availability of heating for 3 weeks of the year, assuming heat would be requested 5 hours each day.

\subsubsection{Start/Stop of Domestic Hot Water Circulation Pumps (Not Implemented)}

In larger buildings requiring substantial use of domestic hot water (DHW), hot water distribution pipes are normally of such length between the water's heat source and its end use (e.g., the faucet) that significant amounts of water would need to be drained from the pipes before hot water were available. The water standing in the pipes gradually loses its heat to the surroundings, despite use of pipe insulation. To prevent this, buildings utilize DHW circulation lines through which a portion of the hot water is constantly circulated, keeping hot water available at the end use at all times.

However, during the nighttime hours, when little hot water is used, providing this convenience requires running circulation pumps in the circulation lines as well as constantly heating the water circulated. Energy savings can therefore be realized by using the UEMCS (or other clock operated system) to automatically shut off the circulation pumps during these hours. Estimates of the savings ascribed to this application depend on the pipe characteristics (diameter and insulation level) assumed and the length of such pipe involved. Prior estimates of savings for this measure (Broders and McConnell 1991, Purucker and Gettings 1991) varied widely mostly because of the length of pipe assumed in each building and whether the estimate considered the energy required to reheat the water in the morning if pumps were shut off. Further uncertainty is introduced for Baumholder because many administrative buildings are not authorized to have any DHW. One building visited used a demand water heater instead. Thus, no savings could be attributed for this measure in such buildings.

Despite the uncertainty, general opinion appears to support the conviction that implementation of this measure saves substantial energy. With additional data, engineering estimates could be performed to support this claim. 


\subsubsection{Start/Stop}

The Honeywell, Messner/Miles and Landis \& Gyr systems are capable of performing simple start/stop applications. The Honeywell and Messner/Miles systems apply start/stop mostly to heating water pumps to reduce consumption during extended periods when buildings are not occupied. Equipment not attached to the UEMCSs can be shut down, but must be done so manually, with no feedback to indicate the equipment has been shut off or if and when it has been restarted. Savings associated with this application cannot be estimated since they depend on individual occupancy schedules of the buildings affected. The start/stop application can also be used to shut off DHW circulation pumps during the night, but the UEMCSs are not used for this purpose. Some buildings use time clocks to accomplish this.

\subsection{SUMMARY OF APPLICATION SAVINGS AND COMPARISON WITH CONSUMPTION TRENDS}

Tahle 7 summarizes the current estimated energy savings for the UEMCS applications implemented at the Baumholder military community. Most values assume no ability of local controllers present before UEMCS implementation to accomplish the same energy savings applications. The savings are based on 1990 total installation consumptions reported in Table 4 .

The Baumholder installation, the largest energy consumer in the community, also has the greatest estimated savings from UEMCS implementation, $38.8 \mathrm{kMBtu} / \mathrm{year}$. However, the majority of this savings should have been realized in 1983 or 1984, when the Honeywell 1000 first became operational (Table 2). Because no annual energy consumption data could be obtained before 198.5, the effect of implementing this system cannot be seen. This estimated savings is less than $6 \%$ of Baumholder's total energy consumption for 1990 (see Table 4). However, the value assumes that only a third of Baumholder is attached to the UEMCS.

The annual UEMCS savings estimated for Neubrücke, $3.4 \mathrm{kMBtu}$, can be compared with the total community energy consumption reduction between 1986 and 1987, because this is the period during which the Neubrücke UEMCS is believed to have become operational. Computed from entries in Table 3, this reduction was $49 \mathrm{kMBtu}$. The $3.4 \mathrm{kMBtu}$ estimated UEMCS savings at Neubrücke is far less. However, to have expected the entire $49 \mathrm{kMBtu}$ reduction to stem from implementation of the UEMCS at Neubrücke would have been unreasonable. Based on installation consumptions reported for 1990 , only $8 \%$ of the total community's consumption can be attributed to Neubrücke, which for 1986 amounts to $106 \mathrm{kMBtu}$. Thus, to ascribe the $49 \mathrm{kMBtu}$ reduction totally to the Neubrücke's UEMCS installation implies that approximately half the installation's total energy consumption was saved by attaching half the total building area to a UEMCS.

Had individual installation annual consumptions over the years of UEMCS implementation been available, observing the effects of the UEMCS in the historical energy usage trends would undoubtedly have been more successful. Consumption at the Baumholder installation is so much greater than at any other installation, effects of conservation efforts at these smaller facilities is easily obscured by even small fractional changes in Baumholder's year-to-year consumption. 


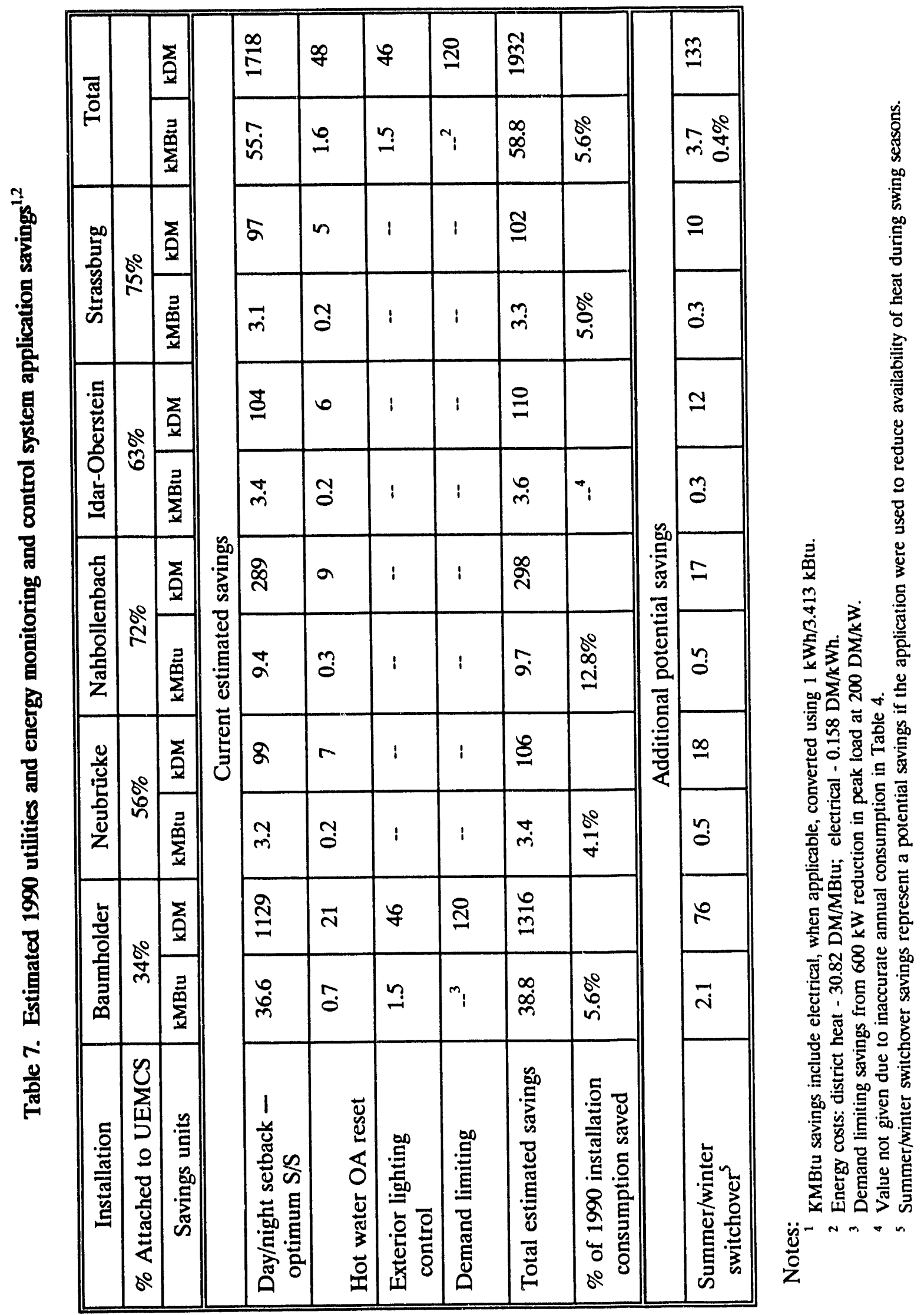


Estimates of energy savings from UEMCS implementation at other installations are also reported in Table 7. Nahbollenbach's relatively high percent savings stem from its high UEMCS implementation percentage, $72 \%$, and elevated savings from optimum start/stop for administrative and warehouse buildings as opposed to smaller night setback savings in housing. No percent savings is reported for Idar-Oberstein because of a lack of accurate reported total energy consumption in Table 4 (no electric consumption was reported).

The Messner/Miles UEMCSs at Nahbollenbach, Idar-Oberstein, and Strassburg Kaserne would be expected to show annual energy consumption reductions beginning in 1989 or 1990 , the same period during which conversion to district heat took place. Therefore, any annual reductions for these years would be expected to show the combined effect of these two projects. The sum of the estimated UEMCS savings for these three installations taken from Table 7 is about $17 \mathrm{kMBtu}$. Table 3 shows annual reductions of $119 \mathrm{kMBtu}$ and $28 \mathrm{kMBtu}$ for the 2 years, respectively. Thus, the estimated UEMCS savings are approximately only $12 \%$ of the two combined consumption reductions. However, it must be noted that the three installations receiving UEMCSs at this time have a combined annual consumption of less than $14 \%$ of the entire community's consumption in 1990 (see Table 4). Thus, the conversion to district heat at Baumholder would be expected to constitute a large fraction of the savings seen during these years.

The total estimated annual energy savings from implementation of the UEMCSs are 59 kMBtu, representing about $6 \%$ of the community's total consumption. Associated monetary savings are DM 1.9 million.

Table 7 also lists an additional site-wide potential energy savings of $3.7 \mathrm{kMBtu}(0.4 \%)$ through a reduction in the heating season using the seasonal switchover capability of the UEMCS. A more significant potential savings would be expected to result from shutting off the DHW pumps for specified hours during the night. 


\section{GENERAL ASSESSMENT OF UTILITIES AND ENERGY MONITORING AND CONTROL SYSTEM BENEFITS}

As stated in Project Planning, Design, and Acquisitions Guidelines-Utility and Energy Monitoring and Control Systems (USAREUR undated), a UEMCS is not limited to applications that save energy or reduce ccsts. A UEMCS can also be a management tool, supporting the functions of the Utilities Division with such diverse applications as utility cost reduction and utility system planning operation, and maintenance.

The mechanical it ilities chief, Ulbig Reinhardt, gave an excellent summary of the additional benefits of a centralized UEMCS system beyond the saving of energy. Items discussed included the following: (1) system failures give an alarm at the central computer, thus aiding in locating and repairing problems quickly; (2) complaints can be analyzed and repaired more easily by first viewing UEMCS-reported parameters associated with the area from which the complaint originated; (3) on responding to maintenance calls, information supplied by the UEMCS is often sufficient to determine who should be sent to the site to respond, rather than first sending a foreman to evaluate the situation; (4) during off-hours, the UEMCSs monitor the installations' systems without having a man on duty; and (5) the ability to have the system perform seasonal switchover initiated from a central location, rather than requiring personnel to visit each mechanical system to perform the alterations manually, exists.

The Baumholder community has benefitted from, and plans to continue implementing, boiler consolidation projects in which individual building boilers are replaced by larger, more efficient boilers that can service a central area. In conjunction with thes, consolidation projects, connections between monitoring devices at the new boilers and existing UEMCSs are being made. Thus, the reduction in the need for boiler supervision is two-fold-fewer boilers to monitor and the ability for the UEMCS operator to monitor multiple boilers from a central location.

The Baumholder UEMCSs also perform the tasks of switching between dual pumps in the hot water lines of district heat and monitoring the pressure differential across key filters, thus giving an indication when they need to be changed or cleaned.

The existence of leaks in the heating water systems can be detected by monitoring the amount of feedwater needed. It is uncertain, though expected, that the UEMCS is involved in this monitoring. Apparatus capable of actually locating leaks, probably by sensing moisture content in water line insulation and pipe jackets, was mentioned as available but not yet attached to the UEMCSs.

The use of a UEMCS to monitor and control the operation of two water treatment plants in the community is an excellent example of systems used for purposes other than strictly energy reduction. Partly because of the use of efficient control by the UEMCSs, the community's cost for water hass been estimated to be 1.2 DM per cubic meter, compared with the city's price of $2.9 \mathrm{DM}$ per cubic meter. The systems assist in performing leak-detecting pressure checks in the water lines to identify leaks and permit easy initiation of pumping water during off-peak hours.

There appears to be general acceptance of the UEMCSs by the base personnel in general and a desire on the part of the operators and maintenance personnel to continue to improve and expand the system. However, with the current downsizing of the U.S. presence in the area, other matters 
take priority over these objectives. The energy conservation efforts at the community are described as "low key but effective." There has been no requirement to make presentations of the base energy programs for several years and no major energy awareness program initiated for about 8 years. Some energy office personnel expressed discouragement that no funds were available to plan such programs or to perform minimum inspection of conditions in the base's buildings. Examples of situations indicating the need for these activities were the jamming of timed hallway lights, heating of unoccupied spaces, and use of entry-way heaters in August. Building coordinators have been assigned, but not overseen, which likely contributes to some ineffectiveness. 


\section{CONCLUSIONS}

Only relatively broad conclusions can be drawn from the information obtained from study of the UEMCSs at the Baumholder military community. Historical consumption data for those installations receiving UEMCSs would have permitted means of demonstrating the effect of these systems' implementation. Consumption data for 1990 were of great value, though inconsistencies existed.

- The Baumholder installation within the community consumes $66 \%$ of the community's total energy consumption. No other single installation consumes more than $8 \%$ of the total.

- The Baumholder Utilities Division has acted wisely in implementing UEMCS equipment at its largest energy consuming installations, particularly Baumholder.

- Substantial reductions in thermal energy consumption over the entire Baumholder military community have occurred from 1986 through 1990 because of implementation of UEMCS equipment and the conversion from local fossil fuel boilers to purchased district heat. Thermal consumption has decreased nearly $25 \%$ over this time. This reduction follows an unexplained, or possibly erroneous, $10 \%$ increase in consumption from 1985 to 1986.

- The clearest trend in examining the annual community energy consumption by fuel is the impact of converting heating plants from coal and oil to hot water district heating between 1987 and 1990 . Thermal energy consumption decreased $21 \%$ over this period. However, if an estimate of the district heating plant efficiency is used to convert this savings to the source fuels, the reduction may be more nearly $10 \%$.

- The trends seen in annual thermal energy consumption normalized for total community square footage and heating degree days $\left(\mathrm{MBtu} / \mathrm{HDD} / \mathrm{ft}^{2}\right.$ ) resemble those for actual consumption (MBtu).

- Normalized electrical energy consumption (MBtu/kft ${ }^{2}$ ) increased $13 \%$ between 1985 and 1988 , then decreased $7 \%$ from 1988 to 1990 . The only UEMCS equipment affecting electrical use is the Landis \& Gyr demand limiting system. This equipment affects mainly electrical demand, although its control of exterior lighting would have a small effect on consumption. Thus, no consistent correlation appears to exist between historical electrical consumption trends and UEMCS implementation.

- Baumholder's 1990 normalized total and thermal energy consumptions are higher than at two other communities studied. However, the values are not inordinately high and will likely decrease as a larger fraction of the Smith Barracks is connected to the UEMCS.

- Lack of annual energy consumption data by individual installation makes direct association of energy reductions with the implementation of specific UEMCSs difficult. The total absence of any data before 1985 prevents identifying the effects of the UEMCSs at Baumholder, the largest energy consumer in the community. 
- Facilities currently under UEMCS control have normalized thermal consumptions consistent with well managed systems, although the value for Strassburg Kaserne is higher than at the other sites.

- Thermal energy consumption at the community's missile sites is significantly higher than at other facilities.

- The community's Utilities Division plans for UEMCS expansion are correctly focused on its largest energy consuming facilities.

- The community's greatest UEMCS-related energy savings result from application of optimum start/stop and day/night setback at its Smith Barracks facility within the Baumholder installation.

- Current estimated annual UEMCS-related savings are DM 1.9 million and $59 \mathrm{kMBtu}$ per year, representing about $6 \%$ of the community's total energy consumption.

- Additional potential UEMCS-related savings exist through implementing shutdown of DHW circulation pumps during the nighttime and shortening the heating season with use of the seasonal switchover capabilities of the UEMCS. Savings for the former could be substantial, but require additional information to estimate. Savings from the switchover are estimated to be only DM 0.1 million and less than $4 \mathrm{kMBtu}$ per year.

- The overhead data transmission lines associated with the Honeywell 1000 and the telephone cables used with the Honeywell 5600 systems are old and frequently unreliable. 


\section{RECOMMENDATIONS}

Numerous opportunities exist for expanding the use and coverage of UEMCSs at Baumholder. Many have already been envisioned by the utilities personnel. The following recommendations result from observing current site conditions and presently operating systems as well as discussion with Baumholder Utilities Division personnel. However, implementation of any of the items would require further examination of relevant data and specific conditions and estimation of potential benefits and cost.

- Expanding use of the demand limiting capability of the Landis \& Gyr system is ongoing with considerable potential yet to be tapped. Baumholder should continue expansion of this capability as long as electric rate structure continues to offer savings for the resulting peak reductions achievable. Savings may result from lowering the peak ceiling as well as monthly demand. Examination of current ceilings in the rate structure should be made to insure such a reduction may not already provide savings.

- Baumholder is the largest energy consuming installation in the community, yet only about a third of the building area is serviced by a UEMCS. Thus, expansion of UEMCS control at this installation offers the greatest potential for increased UEMCS energy savings. A primary obstacle to increasing this control appears to be the saturation of the Honeywell 1000 system's computer. Serious consideration should be given to the most cost-effective means to remedy this situation. The possibility of using available memory on the Honeywell 5600 computer associated with the Excel system was indicated by the utility's personnel. An upgrade of the 1000 system itself may be feasible and likely preferable if sharing the 5600's capacity might eventually limit the 5600's ability to expand.

- Provided there exists available capacity with existing UEMCS central computers, UEMCS expansion at Baumholder could include the hospital, the QM area, and Wetzel and Smith family housing. Implementation may be performed in conjunction with boiler consolidation, currently planned for the QM area.

- Present UEMCS equipment should be used to provide shutoff of DHW circulation pumps during nighttime hours in family housing complexes and applicable administrative buildings. Schedules of shutoff can be tailored to each individual facility's needs.

- The extension of the Honeywell 5600 UEMCS servicing the Neubrücke Hospital complex to include the associated family housing area appears to be a natural UEMCS expansion project since a portion of the necessary equipment is already in place. Because the majority of energy savings resulting from such implementation is expected to come from night setback and DHW circulation pump control, currently operating local controllers should be examined to determine whether these applications are already being reliably performed. Benefits not directly related to energy should also be considered.

- Heating hot water leak detection equipment was indicated as "in place" but not yet connected to the UEMCS. Additional leak detection equipment for potable water was said to be on order. Though little additional information was obtained relevant to this equipment, it would be assumed advantageous to complete its intended installation. 
- Tracking of annual energy consumptions and costs by fuel for each installation should provide the ability to better verify expected energy use reductions resulting from implementation of conservation measures or detection of any unusual energy use abnormalities. Current Army reporting requirements dictate monitoring of community-wide fuel consumption and cost data, likely compiled from the desired additional data.

- Although individual building coordinators have been assigned, there appears little if any direct supervision of their efforts or guidance given with regards to energy conservation opportunities. "No conservation measure or energy system such as a UEMCS can achieve its full potential unless building occupants consider energy conservation worthwhile" (Broders and McConnell 1991). A moderate effort should be established to coordinate energy awareness and to insure application of sound energy conservation practices at the end-user level. The DEH favors monitoring electric, water, and heat at individual family housing buildings to insure proper operation of the UEMCS (Seastrum 1992). If this were done, considerable information could also be gained regarding energy practices of the end-user, which could lead to greater energy conservation.

- In coordination with the Directorate of Information and Management, the DEH should test and evaluate the condition and quality of data transmission lines and repair deficiencies or replace as required.

The following items are of less certain benefit or practicality, but should still be considered, particularly in long-range planning of energy conservation efforts.

- Opportunities for the consolidation of individual, small, older heating plants into a smaller number of new higher-efficiency plants should be investigated. UEMCS installation can often be performed with less expense if coordinated with such consolidation efforts. The Baumholder DEH has indicated support for this course of action (Seastrum 1992). In remote locations, benefits should be weighed against those also found to result from replacement of individual boilers with new more reliable, highly-efficient boilers on a one-to-one basis.

- Installation of a UEMCS at the Hoppstådten waterworks, airfield, and sewage treatment plant may be cost-effective since communications lines for the Honeywell 5600 system run near the installation. However, total energy consumption at Hoppstådten in 1990 was less than half and thermal consumption less than a third of the values seen at any other installation already having UEMCS control. Thus additional study would be required to ensure economic justification. UEMCS expansion may be warranted on other than monetary or energy considerations. The Baumholder DEH indicates that "[P]riority has to be given to the entire Baumholder area to utilize the UEMCS system at 100\% efficiency" (Seastrum 1992).

- The existing Messner/Miles and Honeywell 5600 systems likely have capabilities for additional monitoring and control applications not currently utilized. The key factor affecting the costeffectiveness of implementing such applications is the cost of connecting the added local controls and instrumentation to either existing or new field interface devices and linking these to existing DTM to the central computer. Cursory feasibility studies could be performed for so extending these systems to include the following applications: 
1. Control of exterior lighting (similar to that now employed at Baumholder) - Often specialized schedules can be used to increase savings over simple day/night operation.

2. Boiler monitoring - Utilities Division personnel indicated that despite extensive use of district heat, there were still 50-55 individual boilers, believed to refer to the Smith Barracks facility alone.

3. Demand limiting, if significantly large individual electric consumers are available.

- Lightning damage has been reported in several instances during the study of Army UEMCSs in Germany. A review of the Army Corps of Engineers guide specifications and/or their application should be made to establish whether such occurrences could have been avoided.

- A comparison of maintenance experiences at Baumholder and Heidelberg may be beneficial in determining if problems with contracting out major repairs at Baumholder might be alleviated. 


\section{REFERENCES}

Broders, M. A., and B. W. McConnell 1991. Evaluation of the Computerized Utilities Energy Monitoring and Control System Installed at the U.S. Army, Europe, 26th Support Group, Heidelberg, Germany, ORNL/CON-320, Martin Marietta Energy Systems, Inc., Oak Ridge National Laboratory, Oak Ridge, Tenn.

"Good News on the Setback Front" 1991. Home Energy 8(1), Berkeley, California.

NBSIR (National Bureau of Standards) 1984. Performance and Selection Criteria for Mechanical Energy Saving Retrofit Options for Single-Family Residences, NBSIR84-2870, U.S. Department of Commerce, Washington, D.C.

NCEL (Naval Civil Engineering Laboratory) 1992. Standardized EMCS Energy Savings Calculations, CR82.030, Department of the Navy, Port Hueneme, California.

Purucker, S. L., and M. B. Gettings 1991. Evaluation of the Computerized Utilities Energy Monitoring and Control System Installed at the U.S. Military Community at Göppingen, Germany, ORNL/CON342, Martin Marietta Energy Systems, Inc., Oak Ridge National Laboratory, Oak Ridge Tenn.

Seastrum, D. J. (DEH Baumholder) 1992. Memo to Jeff Mitchell, HQ USAREUR, September 24, 1992.

USAREUR (U.S. Army, Europe) undated. Project Planning, Design and Acquisitions Guidelines-Utility and Energy Monitoring and Control Systems, Directorate of Engineering and Housing, Heidelberg, Germany. 

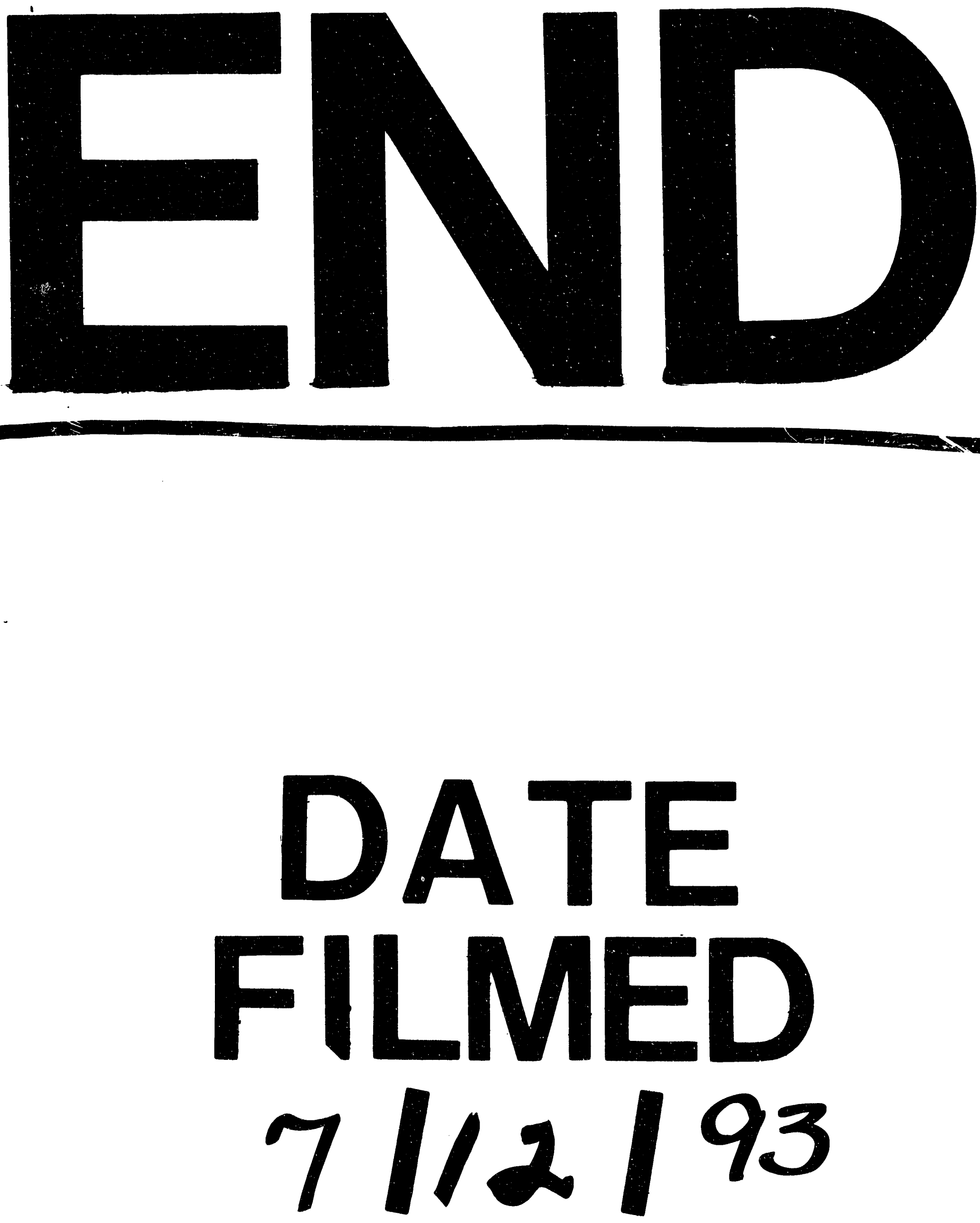
